\title{
PARTICLE ENGULFMENT AND PUSHING BY SOLIDIFYING \\ INTERFACES \\ (PEPSI)
}

FINAL REPORT

August 16, 1993

PRINCIPAL INVESTIGATOR:

Dr. Doru Michael Stefanescu

Che Anibersity Of Alabama

CO-INVESTIGATOR:

Dr. Peter A. Curreri

N(ASA -OMarsfiall Space Flight Center

\section{GRADUATE RESEARCH ASSISTANTS:}

F. Juretsko, H. Pang and R. Phalnikar

The Unibersity Of Alabama

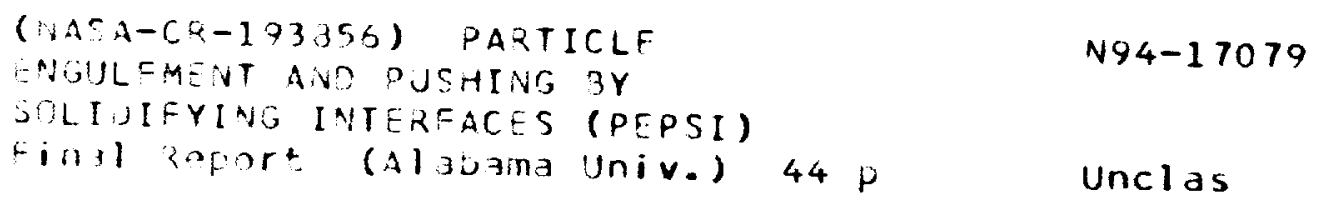




\section{OUTLINE}

1. Introduction 3

2. Task E1 5

3. Task E6 5

4. Task E8 7

$\begin{array}{lll}4.1 & \text { Background } & 7\end{array}$

4.2 Experimental Procedure 9

4.3 Results and Discussion 10

4.4 Conclusions 20

4.5 Appendix 120

5. Task $1.1 \quad 23$

$\begin{array}{lll}5.1 & \text { Background } & 23\end{array}$

5.2 Theoretical Work 27

5.3 Experimental Work 32

$\begin{array}{lll}5.4 & \text { Discussion } & 35\end{array}$

5.5 Summary 40

5.6 Appendix 2 41 


\section{INTRODUCTION}

The preliminary definition phase included the following actions:

1. Producing a Science Requiring Document-Draft

2. Producing a Science Requirement Document- Preliminary

3. Updating the Flight Program Proposal

4. Project Review at NASA-Marshall Space Flight Center

5. Research work as defined in 4.0 schedule, page 9 of the Statement of Work (May 25,1993) (see Fig 1.1)

The first three items of this action plan have been delivered by the University of Alabama to NASA according to schedule. A Project Review Meeting was held at MSFC on June 29, 1993. Consequently, this part of the report will address the results of the research work performed in the Solidification Laboratory at the University of Alabama during the first six month of the project.

The presentation of the experimental and theoretical work will correspond directly to the schedule given in Fig. 1.1. Tasks referred to in this report are E1, E6, E8 and T1.1. 


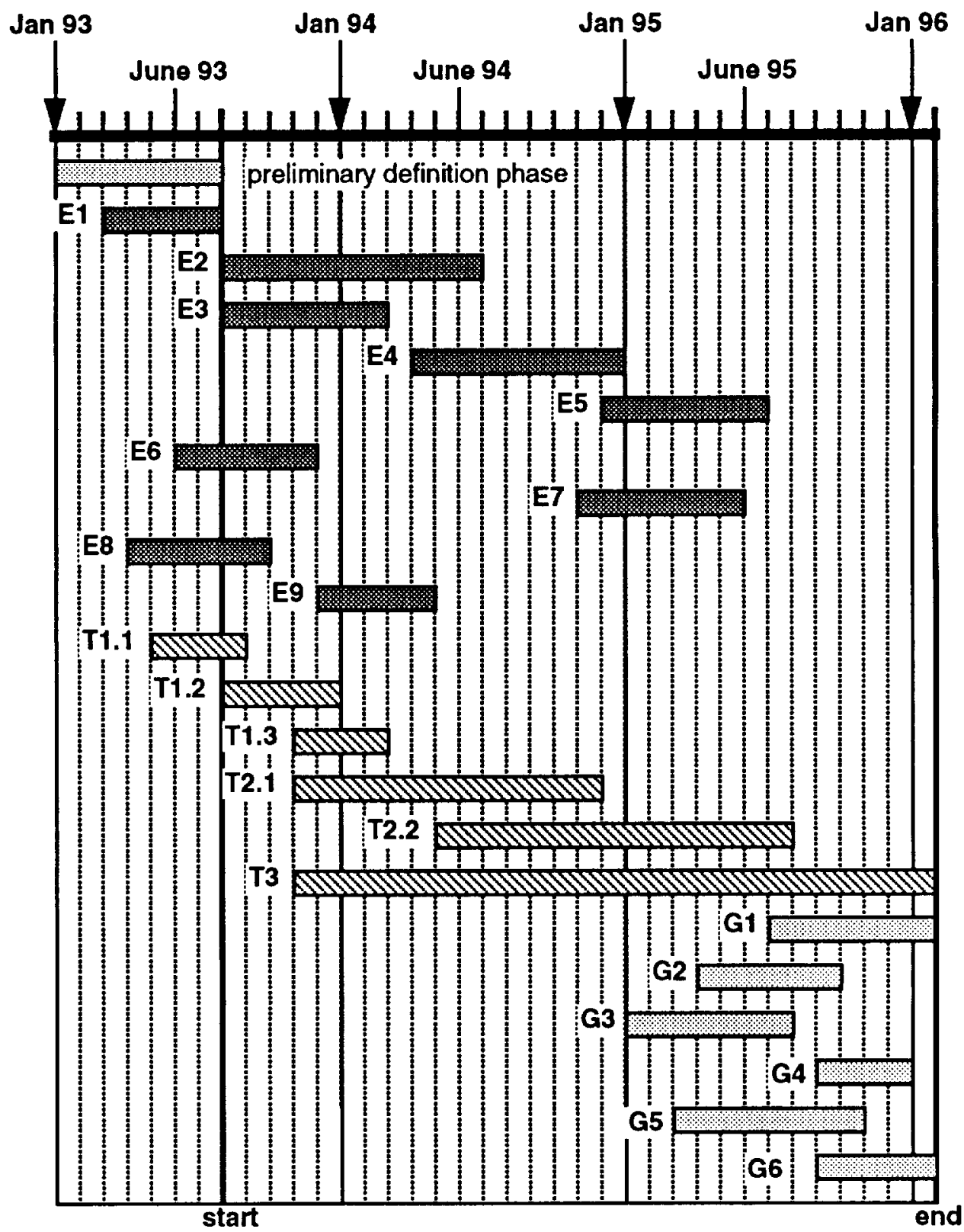

Figure 1.1 Schedule of the NASAPEPSI project from Jan. '93 till Feb. '96. 


\section{TASK E1}

The scope of this task was testing and acceptance for operation of the Bridgman directional solidification furnace.

The Bridgman directional solidification furnace was refurbished. This furnace can heat up to $1600{ }^{\circ} \mathrm{C}$. Directional solidification can be performed in both the vertical and horizontal directions using this furnace. Some modifications were made to the initial design to increase its service life. Tungsten-Rhenium heating elements were replaced by Platinum-Rhodium elements to increase stability. The thermocouple connectors and power controllers were modified accordingly. Water connection to a pressure switch was introduced as a safety measure. The furnace is now ready for final testing. After the final testing, it will be interfaced with a computer to program the furnace operation.

\section{TASK E6}

The objective of this task was to design and build a resistance furnace with quenching capabilities that will be used to evaluate the local growth velocity of equiaxed grains.

The design of the resistance furnace has been completed. This furnace uses molybdenum heating elements and it can heat to $1600^{\circ} \mathrm{C}$. It can work in vacuum as well as argon atmosphere. Quenching will be done by the dropbottom technique. The sketch of this resistance furnace is given in Fig. 3.1.

The furnace will be built after receiving all the parts, which are being ordered presently. 


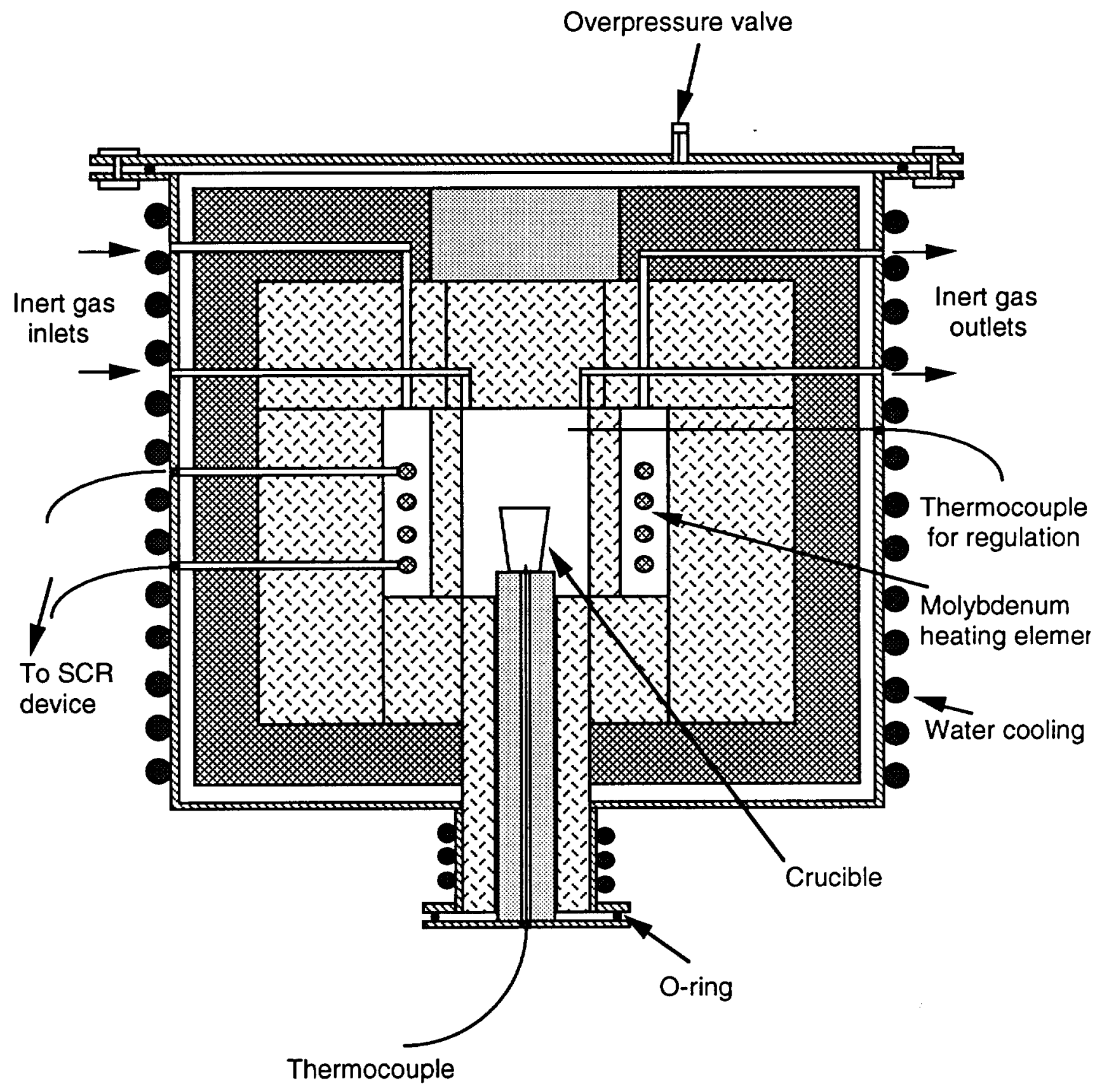

Refractory

$\checkmark$ Porous refractory

Copper

Scale : $\frac{}{1^{\prime \prime}}$

Stainless steel

Alumina mat

Figure 3.1 Sketch of the resistance furnace. 


\section{TASK E8}

The objective of this task is to validate the model developed under task $T$ 2.1 using transparent organic materials. It must be noted that, since the physics of particle pushing by cellular interfaces is not clearly understood, it was necessary to perform the experimental task before the development of the model.

\subsection{Background}

Particle pushing or engulfment by advancing liquid/solid interfaces is relevant to a diversity of problems including particle chromatography, frost heaving, growth of semiconductor crystals, inclusions in steel, and metal matrix composites. The subject has received attention from experimentalists[4.1-4.6] and theoreticians alike.[4.1,4.3,4.6,4.7-4.11]

It is generally accepted that insoluble particles can either be pushed ahead by the interface, or engulfed in the solid phase. The behavior of the particles at the solid/liquid interface depends on the interface velocity. It has been demonstrated experimentally that there exists a critical growth velocity, below which the particles will be pushed by the interface, and above which they will be engulfed.[4.1-4.7] Engulfment will normally lead to uniform distribution of particles, while pushing will result in particle segregation. If the interfaces converge on one another, as is the case in equiaxed solidification, the particle will be eventually entrapped in the solid at the end of local solidification. It is thus of great interest to characterize the critical velocity as a function of materials parameters and processing variables, to ultimately control particle distribution in the matrix.

In a recently published paper, [4.12] an analytical model was proposed. It involved the following analysis:

1) solving the temperature field for the particle/matrix configuration;

2) calculating the shape of solid/liquid interface in the vicinity of the particle;

3) calculating the forces acting on the particle;

4) establishing the critical condition for the pushing/engulfment transition.

The following equation was obtained for the equilibrium solidification velocity for the pushing/engulfment transition: 


$$
V_{e}=\frac{d}{3 \eta \mu}\left[\frac{\Delta \sigma_{0}}{r}\left(\frac{a_{0}}{a_{0}+d}\right)^{n}+\frac{2 r \Delta \rho g}{3 \mu}\right]
$$

where $d$ is the particle-interface distance, $\eta$ is the liquid viscosity, $\mu=K_{p} / K_{L}$ is the thermal conductivity ratio, $D s_{o}$ is the interface surface energy, $a_{o}$ is the interatomic distance, $\Delta \rho$ is the density difference between the particle and the molten matrix, $r$ is the radius of the particle and $n$ can take a range of values from 1-7 depending on the various interactions (Coulombic, Van der Walls, etc.) between the particle atoms and the melt interface atoms. If gravity effects are neglected, which is reasonable for horizontal solidification, the critical velocity (maximum equilibrium velocity) is:

$$
V_{c}=\frac{a_{o}}{3 \eta \mu(n-1)} \frac{\Delta \sigma_{o}}{r}\left(\frac{n-1}{n}\right)^{n}
$$

Computer fitting of numerous experimental results [4.3] produced an equation similar to $\mathrm{Eq}(4.3)$ :

$$
\mathrm{V}_{\mathrm{c}}=\frac{\mathrm{C}}{\mathrm{r}^{\mathrm{m}}}
$$

where $C$ is a constant and the exponent $m$ ranges from 0.28 to 0.9 .

Equation (4.2) has been derived for the case of planar liquid/solid interface. However, under most practical growth conditions, the microstructure of alloys of commercial interest will be either cellular, dendritic or equiaxed. It is expected that the interaction between particles and non planar interfaces will be significantly different.

Although some experimental studies have been carried out in metallic system with non planar interfaces [4.13], a clear understanding of the particle/interface interaction is not yet available. The main difficulty is the impossibility of phenomena visualization because of the opacity of the systems used. This problem can be avoided by using organic transparent analogs of the metallic systems such as succinonitrile.

Recently, some experimental work was conducted to examine the effect of particles on the morphological changes and on the nature of the entrapment processes in a transparent organic system. ${ }^{[4.14]}$ It was shown that the presence 
of a particle alters the solute gradient at the interface segment facing the particle. This causes interface perturbation. However, the effect of interface morphology on the pushing/engulfment transition was not documented. In another recent paper [4.12], experiments were conducted with succinonitrile and $\mathrm{SiC}$ particles. It was found out that, while the behavior described by equation (4.3) is valid for larger particles, for small particles where $V_{c}$ is rather large, smaller values are obtained for the critical velocity than predicted by the power function.

From the available information it is apparent that a more detailed analysis of the correlation between critical velocity and interface morphology is required.

\subsection{Experimental Procedure}

The matrix materials used in this work were succinonitrile (SCN) as the major component, and distilled water as the minor component. The following compositions were used: pure SCN ( $99 \%$ purity), SCN $+0.5 w t \%$ water, and SCN $+1 \mathrm{wt} \%$ water.

The particles used in this study were polystyrene spheres with radii ranging from 0.5 to $7.5 \mu \mathrm{m}$. Directional solidification experiments were conducted in an experimental setup as shown in Fig. 4.1. It consists of a light microscope and a temperature gradient stage (TGS) as described by Ahuja [4.15] The specimens were prepared by stirring particles into the molten SCN matrix, and then pulling the liquid in between the two glass slides through capillarity. The prepared specimen was placed between a hot plate and a cold plate separated by a distance of $6.67 \mathrm{~mm}$. The temperature gradient at the solid/liquid interface, was changed by varying the temperature of the heater. For the experiments described in this paper, the temperature gradient was held constant at either 108 $\mathrm{K} / \mathrm{cm}$ (soak temperature $\mathrm{T}_{\mathrm{s}}=85^{\circ} \mathrm{C}$ ), or $127 \mathrm{~K} / \mathrm{cm}\left(\mathrm{T}_{\mathrm{s}}=95^{\circ} \mathrm{C}\right.$ ). The translation of the TGS was adjusted through a speed controller. The translation velocity was varied between 1.5 and $17 \mathrm{~mm} / \mathrm{s}$. Particle behavior in front of the moving solid/liquid interface was observed and photographed with the microscope at up to $400 \mathrm{X}$ magnification. The particle size was measured using a stage micrometer and eyepiece reticule. 


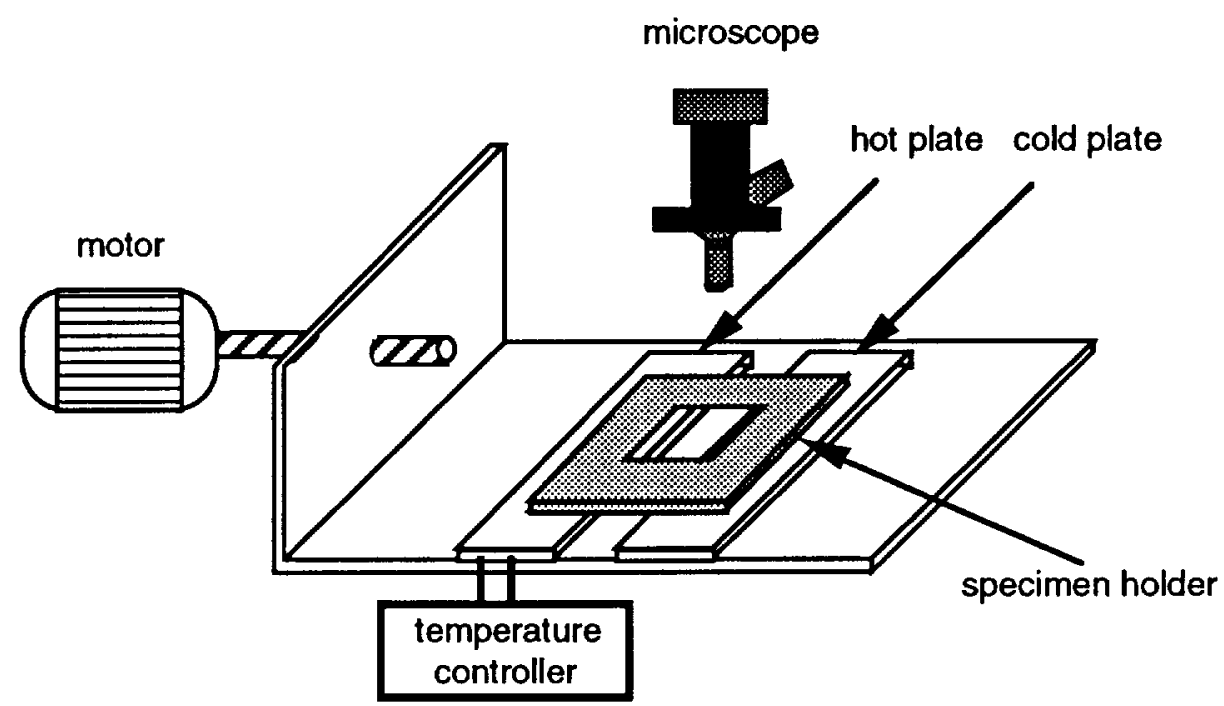

Fig. 4.1. Experimental apparatus for directional solidification of transparent matrix materials.

\subsection{Results and Discussion}

A summary of the experimental results including the influence of composition, particle radius and temperature gradient on the critical velocity for engulfment is given in Table 4.1.

Table 4.1 Summary of directional solidification experiments with the $\mathrm{SCN}-\mathrm{H}_{2} \mathrm{O}$ systems.

\begin{tabular}{|c|c|c|c|c|}
\hline \multirow{2}{*}{$\begin{array}{c}\text { Particle radius, } \\
\mathrm{mm}\end{array}$} & \multicolumn{4}{|c|}{ Critical velocity, mm/s } \\
\cline { 2 - 5 } & $\mathrm{SCN}$ & $\mathrm{SCN}+0.5 \% \mathrm{H}_{2} \mathrm{O}$ & $\mathrm{SCN}+1 \% \mathrm{H}_{2} \mathrm{O}$ & $\mathrm{SCN}+1 \% \mathrm{H}_{2} \mathrm{O}$ \\
& $\mathrm{G}_{\mathrm{L}=108 \mathrm{~K} / \mathrm{cm}}$ & $\mathrm{G}_{L}=108 \mathrm{~K} / \mathrm{cm}$ & $\mathrm{G}_{\mathrm{L}}=108 \mathrm{~K} / \mathrm{cm}$ & $\mathrm{G}_{L}=127 \mathrm{~K} / \mathrm{cm}$ \\
\hline 0.65 & 16.80 & 10.10 & 6.31 & 8.42 \\
1.25 & 12.63 & 10.10 & 6.31 & 8.41 \\
1.90 & $\mathrm{ND}$ & 8.42 & $\mathrm{ND}$ & 7.21 \\
2.50 & 6.74 & 6.31 & 4.21 & 5.61 \\
3.15 & 3.37 & 5.60 & 3.88 & 5.56 \\
3.78 & 2.66 & 2.50 & $\mathrm{ND}$ & 4.21 \\
4.37 & $\mathrm{ND}$ & $\mathrm{ND}$ & 1.68 & $\mathrm{ND}$ \\
4.41 & $\mathrm{ND}$ & $\mathrm{ND}$ & $\mathrm{ND}$ & 2.53 \\
\hline
\end{tabular}

ND: not determined 


\section{A Pure SCN.}

The experimental conditions were varied such that pushing or engulfment of polystyrene particles in SCN were observed. Fig. 4.2 shows a sequence of photographs demonstrating engulfment of a large polystyrene sphere $(r=5.6$ $\mu \mathrm{m}$ ) in SCN solidifying with a plane front. The solidification velocity was 1.48 $\mu \mathrm{m} / \mathrm{s}$ and the temperature gradient was of $108 \mathrm{KJcm}$. It can be noticed that the liquid/solid interface is distorted by the approaching particle, and a depression forms. This type of distortion was observed in all the experiments conducted in this work. However, according to the proponents of the "thermal conductivity criterion" model [4.8,4.16], when $\mu=\mathrm{K}_{\mathrm{P}} / \mathrm{K}_{\mathrm{L}}<1$, which is the case for the system polystyrene particles - SCN used in this study, a bump rather than a depression should form at the liquid/solid interface. Indeed, a qualitative analysis of the thermal field by Bolling and Cisse [4.8], as well as the analytical model proposed by Stefanescu et al. $[4.6,4.12]$, suggest the formation of such bumps on the interface. Nevertheless, these analyses ignore the latent heat evolved during solidification. This heat can be "trapped" between the particle and the interface, because of the lower thermal conductivity of the particle. Thus the interface will be depressed, and a depression rather than a bump should form. Indeed, a numerical model proposed by Sasikumar et al. [4.10], which includes the entropy of fusion, describes the formation of a depression at the interface even for $\mu<1$.

Furthermore, it is reasonable to assume that, since the "pure" SCN contained about $1 \%$ impurities solute was rejected and piled-up in the liquid film between the particle and the solid/liquid interface. This solute accumulation will result in a temperature depression at the interface, and thus may favor formation of a depression.

For smaller particles pushing was easily observed. This is illustrated in Fig. 4.3 for two small polystyrene spheres having radii of 1.9 and $3.0 \mu \mathrm{m}$, respectively. The particles are pushed by the planar SCN solid/liquid interface at the imposed velocity of $5.5 \mu \mathrm{m} / \mathrm{s}$. As evident from Table 4.1 , this velocity is smaller than the critical value. A depression of height smaller than the radius of the particles is observed. 


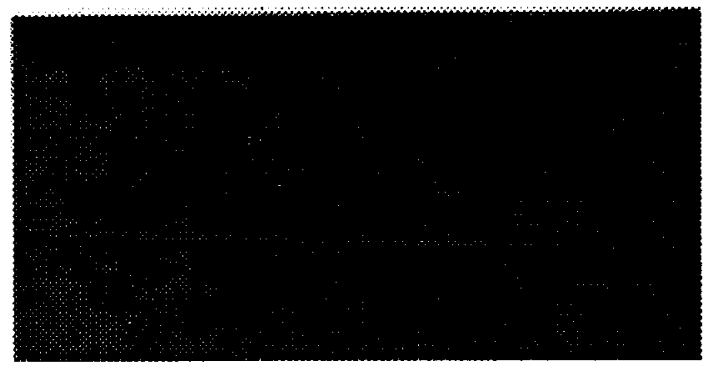

a)

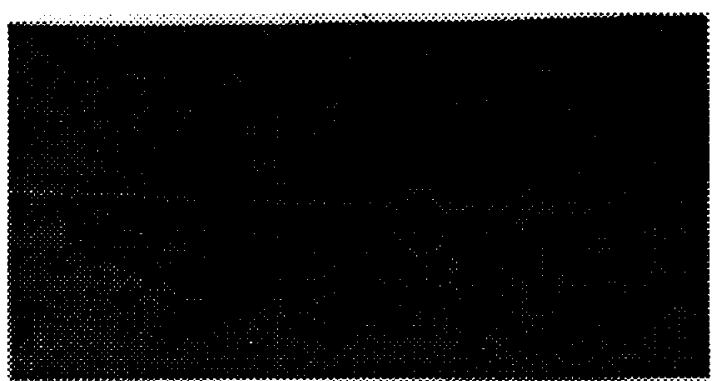

c)

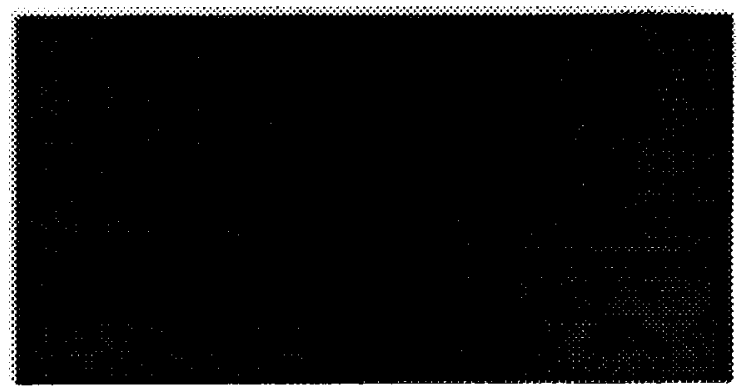

b)

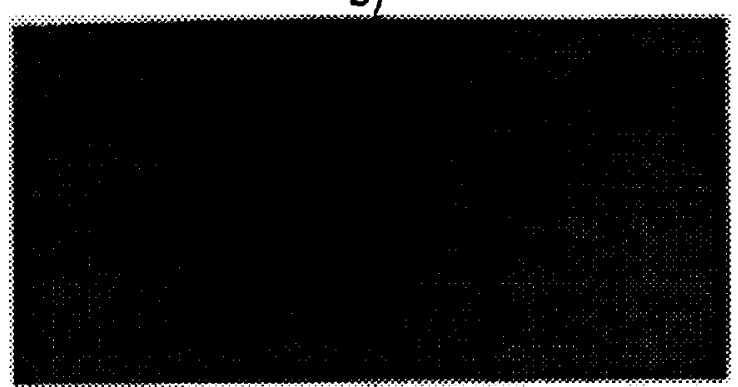

d)

Fig. 4.2. A spherical polystyrene particle $(r=5.6 \mu \mathrm{m})$ being engulfed by the planar SCN solid/liquid interface at $V=1.48 \mu \mathrm{m} / \mathrm{s}$ and $\mathrm{GL}_{\mathrm{L}}=108 \mathrm{~K} / \mathrm{cm}$. (a)-(d) increasing time.
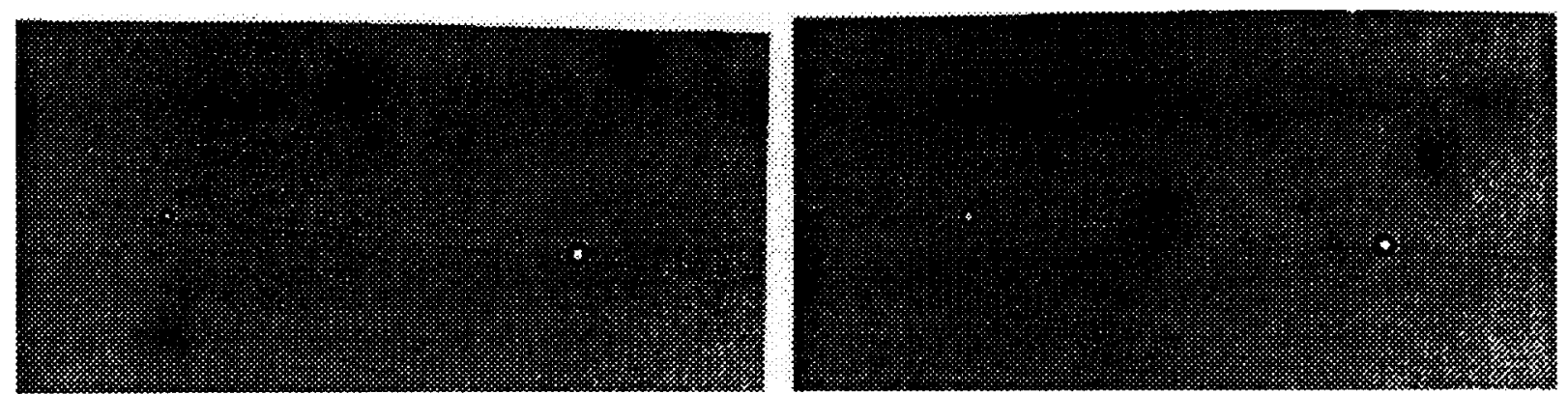

Fig. 4.3. Two polystyrene spherical particles $(r=1.9 \mu \mathrm{m}$ and $3.0 \mu \mathrm{m})$ being pushed by the planar SCN solid/liquid interface at $V=5.5 \mu \mathrm{m} / \mathrm{s}$ and $G_{L}=108 \mathrm{~K} / \mathrm{cm}$.

The dependence of the critical velocity on particle radius is plotted in Fig. 4.4. The full squares represent the data for velocities resulting in planar interface. The empty squares correspond to velocities at which cellular interface was obtained. Apparently, the critical velocity decreases with increasing particle size as predicted by theoretical models. The solid lines on the figure are the least square best fit through the data points with $\mathrm{Eq}(4.3)$, assuming that $\mathrm{m}=1$, as 
suggested by Eq (4.2). The corresponding equations, for velocity expressed in $\mu \mathrm{m} / \mathrm{s}$, are:

$$
\begin{array}{ll}
\text { for planar interface only } & V_{c}=\frac{13.5}{r} \\
\text { for all experimental data } & V_{c}=\frac{12.1}{r}
\end{array}
$$

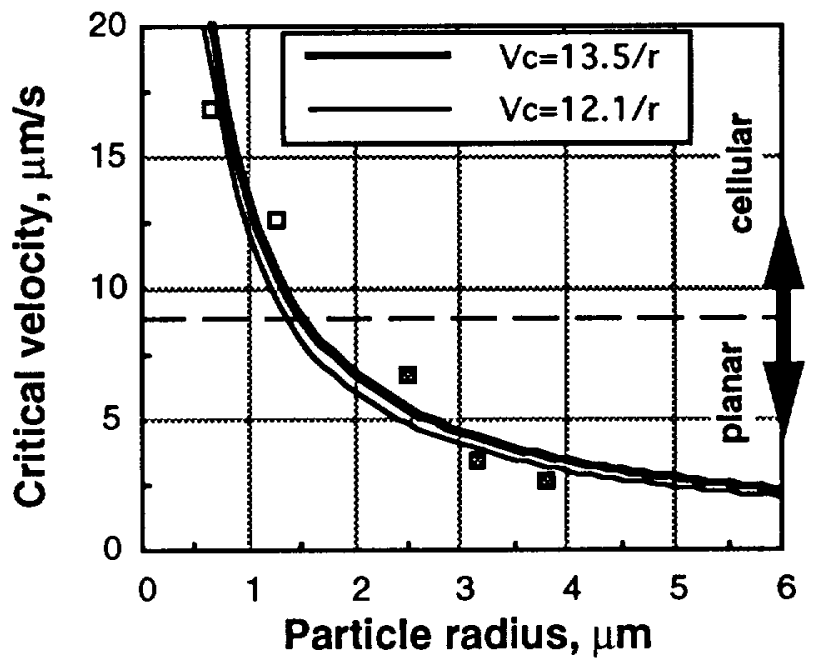

Fig. 4.4. Correlation between the critical velocity and particle radius in pure $\operatorname{SCN}\left(G_{L}=108 \mathrm{~K} / \mathrm{cm}\right)$.

It can be seen that when all data are included, the $V_{c}-r$ curve is moved slightly to the left. This means that the break down of the interface resulted in lower critical velocity than expected for a planar interface. Nevertheless, pushing was still possible. At velocities above the critical velocity, particles were incorporated through engulfment.

These results compare favorably with the experimental findings of Korber et al. [4.17] where $V_{c}$ was found to vary proportionally with $r^{-1}$ for latex particles in an ice-water system.

Taking $n=2$ as proposed in ref. $[4 \cdot 6,4 \cdot 9,4.12]$, Eq.(4.2) can be used to calculate the difference in surface tension, $\Delta \sigma_{0}$. Using constants from the Appendix, one obtains $\Delta \sigma_{0}=2.53 \times 10^{-4} \mathrm{~N} / \mathrm{m}$. When this value is used a good curve fit is obtained for the experimental data in Fig. 4.4. 


\section{B. Succinonitrile-water systems.}

The influence of solute on the critical velocity was studied with polystyrene particles in SCN containing 0.5 or $1.0 \mathrm{wt} \%$ distilled water. In the two-component systems the interface became morphologically unstable at lower growth velocities as compared with pure $\mathrm{SCN}$, because of solute rejection and constitutional undercooling. Cellular structures were readily observed. Figs. 4.5 through 4.7 show particle/interface interaction in $\mathrm{SCN}-0.5 \%$ water as the interface velocity was increased from 2.1 to $8.42 \mu \mathrm{m} / \mathrm{s}$.

In Fig. 4.5 it is seen that two small polystyrene spheres $(r=1.9 \mu \mathrm{m}$ and 3.0 $\mu \mathrm{m}$ ) were pushed by the planar solid/liquid interface with a velocity of $2.1 \mu \mathrm{m} / \mathrm{s}$. The planar interface began to break down as the solidification velocity was increased to $5.05 \mu \mathrm{m} / \mathrm{s}$. At this point, particles were pushed by a non planar interface (Fig. 4.6). The particle with the radius of $3.0 \mu \mathrm{m}$ (particle on the left) was first engulfed by a non planar interface when further increasing the solidification velocity to $8.42 \mu \mathrm{m} / \mathrm{s}$, while the particle with the radius of $1.9 \mu \mathrm{m}$ (particle on the right) was still pushed by the cellular interface, and was eventually entrapped at cells boundaries (Fig. 4.7).
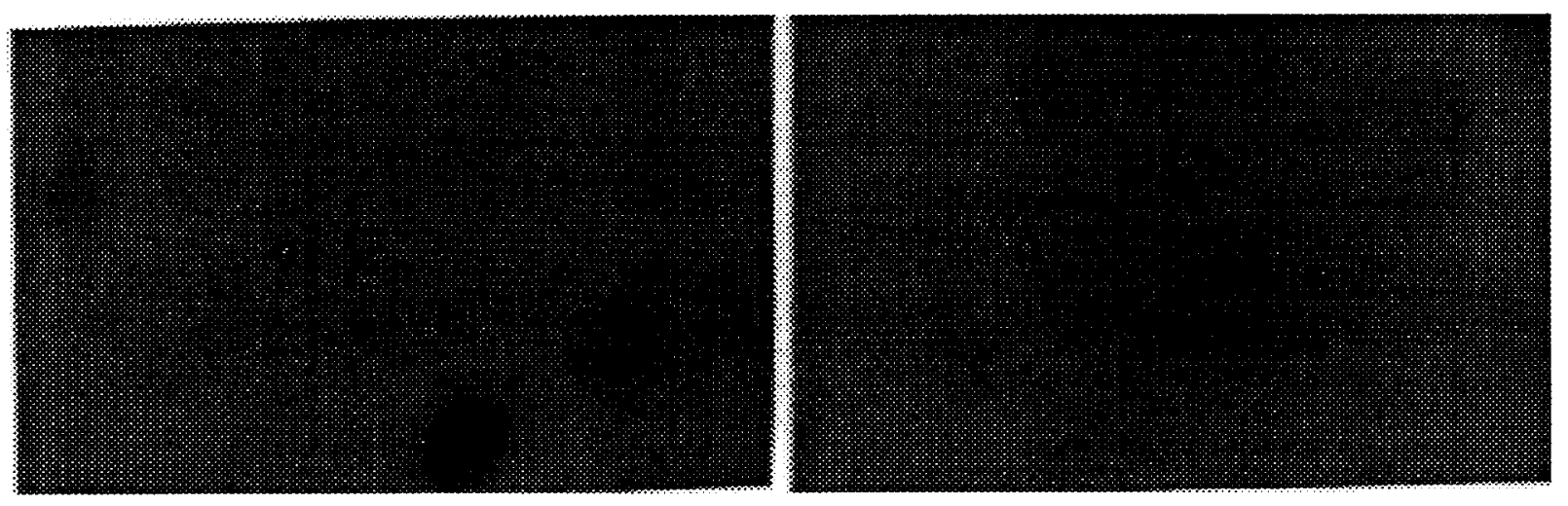

Fig. 4.5. Particle/interface interaction in SCN- 0.5 wt\% water. Two polystyrene spherical particles $(r=1.9 \mu \mathrm{m}$ and $3.0 \mu \mathrm{m})$ are pushed by the planar solid/liquid interface at $V=2.1 \mu \mathrm{m} / \mathrm{s}$ and $G_{L}=108 \mathrm{~K} / \mathrm{cm}$. 

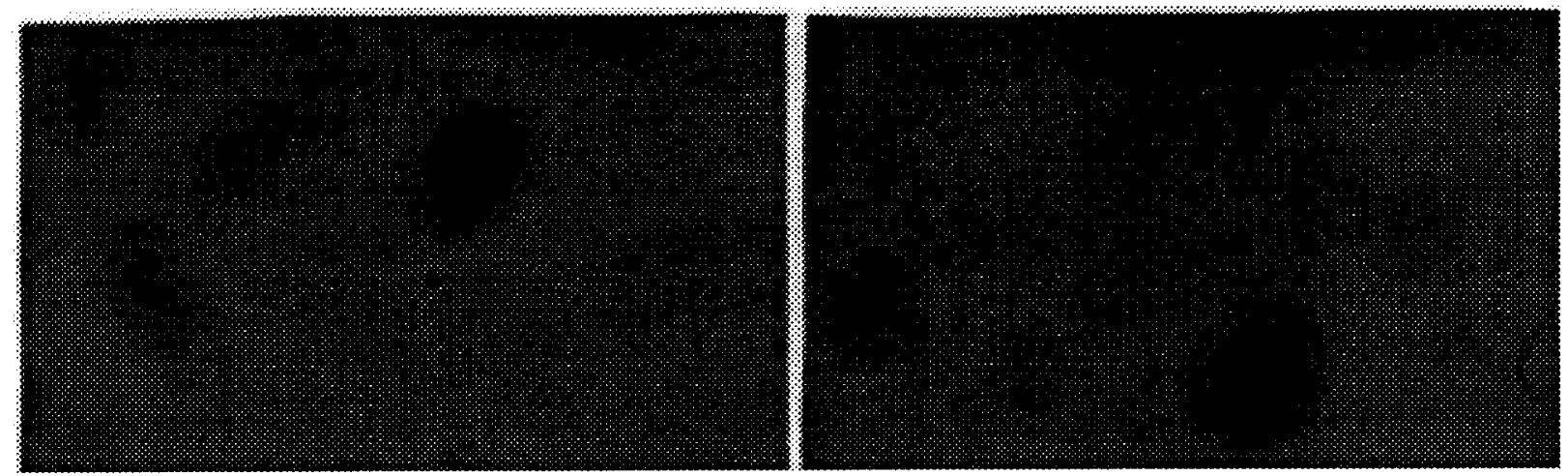

Fig. 4.6. Particle/interface interaction in SCN-0.5 wt\% water. Interface velocity was increased at $V=5.05 \mu \mathrm{m} / \mathrm{s}$. The planar interface begins to break down.

Particles are still pushed by a non planar interface.
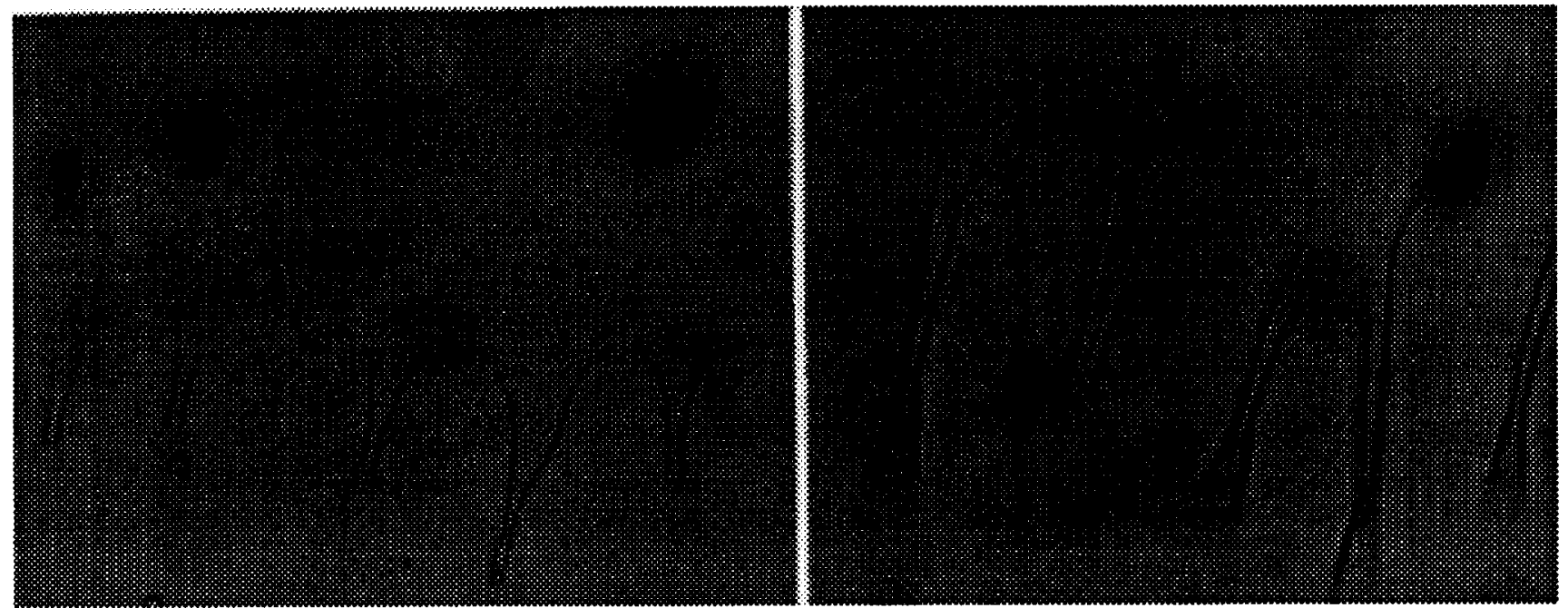

Fig. 4.7. Particle/interface interaction in SCN-0.5 wt\% water. Interface velocity was increased at $V=8.42 \mu \mathrm{m} / \mathrm{s}$. The particle with the radius of $1.9 \mu \mathrm{m}$ is pushed by the cellular interface, then entrapped at cell boundaries.

Similarly, Figs. 4.8 through 4.10 represent the various phases of the solidification process in SCN-1.0 wt\% water when increasing the velocity from 2.1 to $6.31 \mu \mathrm{m} / \mathrm{s}$. Compared with the SCN-0.5 wt\% water system, in the SCN-1.0 wt\% water system, the planar interface began to break down at a lower interface velocity of $3.6 \mu \mathrm{m} / \mathrm{s}$. In general, as expected, the velocity at which interface instability occurs decreases as the water content increases (Fig. 4.11).

On Figs 4.8 and 4.9 it can be seen that some particles pushed by the interface are moving transverse to the interface, until they reach an intercellular 
boundary. Then, these particles continue to be pushed at the cell boundaries. As the interface velocity is further increased to $6.31 \mu \mathrm{m} / \mathrm{s}$, the interface becomes cellular, with subsequent particle entrapment (Fig. 4.10).

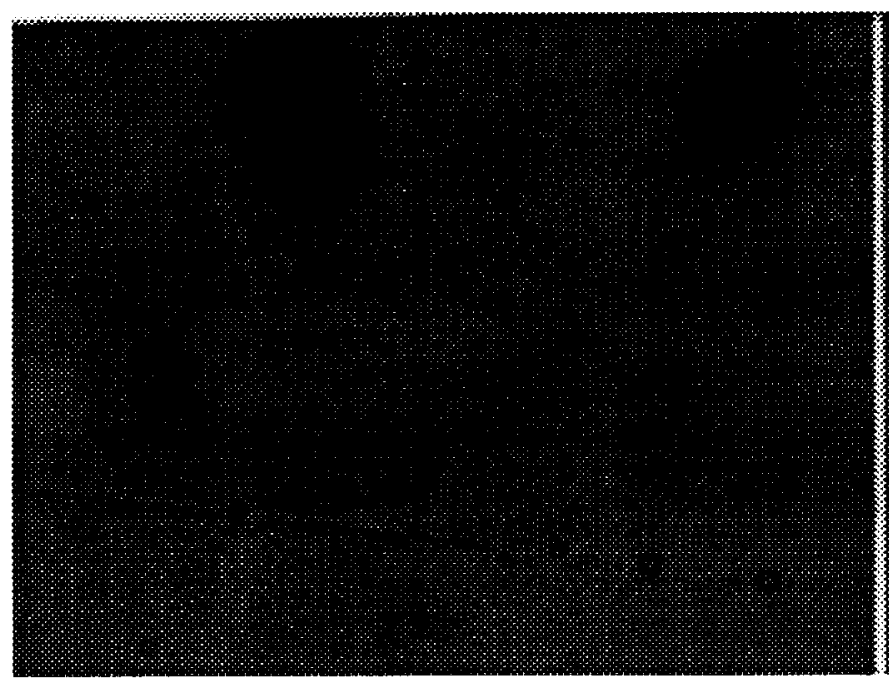

Fig. 4.8. Particle/interface interaction in SCN-1 wt\% water. Particles with radii of 1.9 to $3.1 \mu \mathrm{m}$ are pushed by the planar solid/liquid interface at $V=2.1 \mu \mathrm{m} / \mathrm{s}$ and $\mathrm{GL}_{\mathrm{L}}=108 \mathrm{~K} / \mathrm{cm}$.

Fig. 4.9. Particle/interface interaction in $\mathrm{SCN}-1$ wt\% water. Particles with radii of 1.9 to $3.1 \mu \mathrm{m}$ are still pushed by a solid/liquid interface that has begun to break down at $V=3.6 \mu \mathrm{m} / \mathrm{s}$ and $G_{L}=108 \mathrm{~K} / \mathrm{cm}$. 

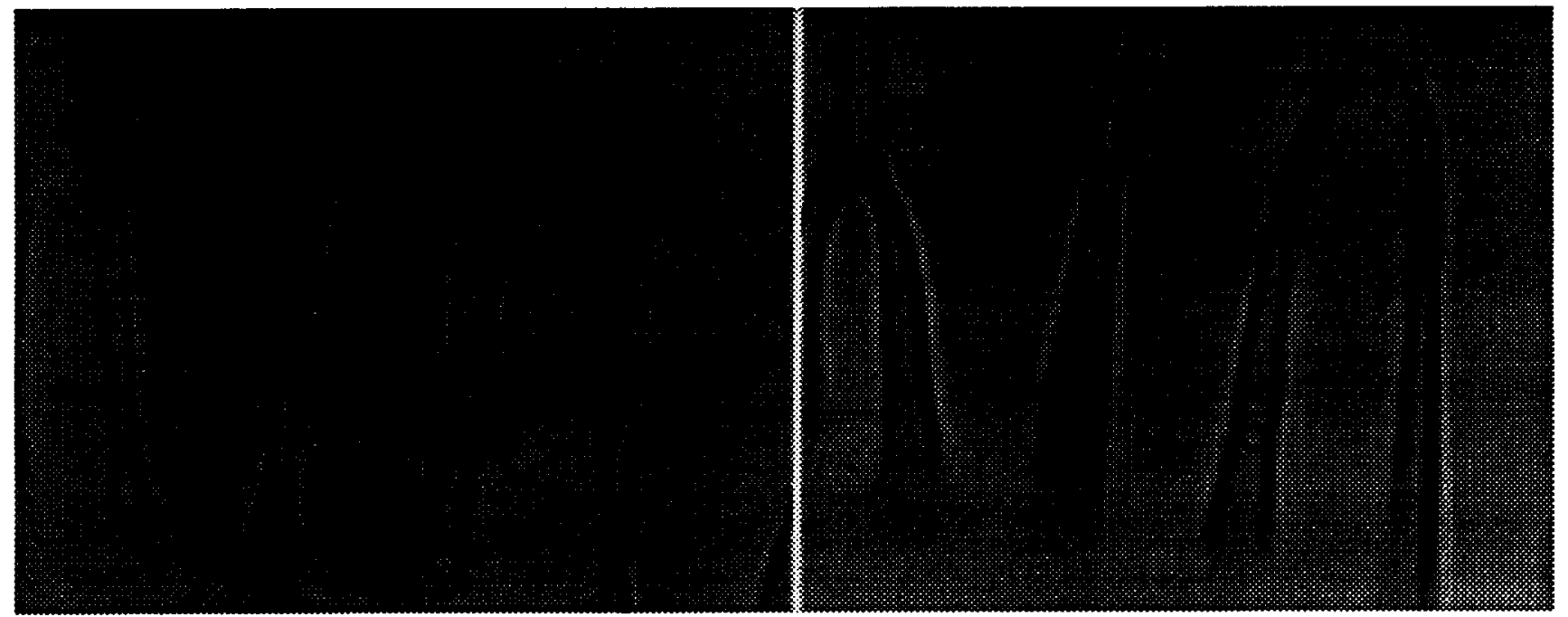

Fig. 4.10. Particle/interface interaction in $\mathrm{SCN}-1 \mathrm{wt} \%$ water. Particles with radii of 1.9 to $3.1 \mu \mathrm{m}$ are entrapped at cell boundaries by a cellular solid/liquid interface at $V=6.31 \mu \mathrm{m} / \mathrm{s}$ and $G_{L}=108 \mathrm{~K} / \mathrm{cm}$.

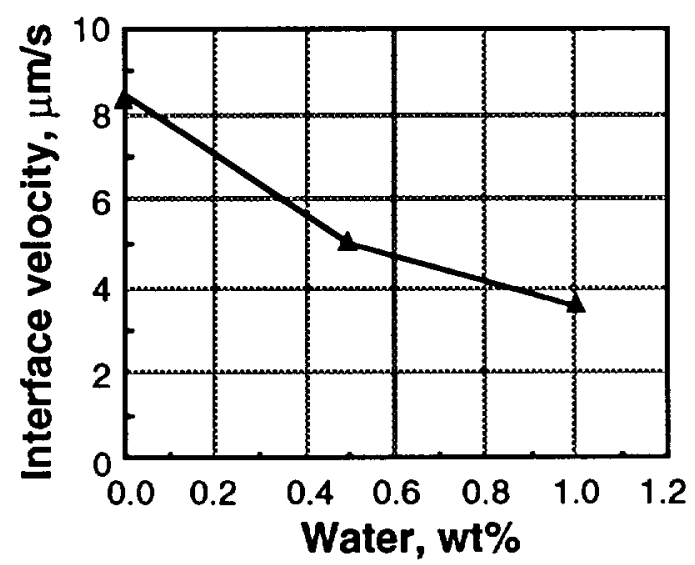

Fig. 4.11. Experimental interface velocity above which the liquid/solid interface becomes unstable as a function of water content $\left(G_{L}=108 \mathrm{~K} / \mathrm{cm}\right)$.

The experimental values for the critical velocity as a function of particle radius for SCN-water systems are plotted in Fig. 4.12. It can be seen that, as the interface becomes unstable, the $\mathrm{Vc}-\mathrm{r}$ correlation strongly deviates from the power function observed for pure SCN (compare with Fig. 4.4). A moderate deviation is observed when particles are engulfed by a non-planar interface. A strong deviation occurs when particles are entrapped by a cellular interface. In general, as the particle size decreases, and the velocity increases, particle incorporation in the solid occurs through entrapment rather than through engulfment. 
All the experimental results for samples solidified under a gradient of 108 $\mathrm{K} / \mathrm{cm}$ are plotted in Fig. 4.13. The full points represent as before the data for the experiments were the solid/liquid interface remained planar. The curve represents the best fit through all the points obtained for planar interface, that is, including SCN, SCN $+0.5 \%$ water, and $\mathrm{SCN}+1.0 \%$ water. The equation corresponding to this curve is:

$$
V_{c}=\frac{12.8}{r}
$$

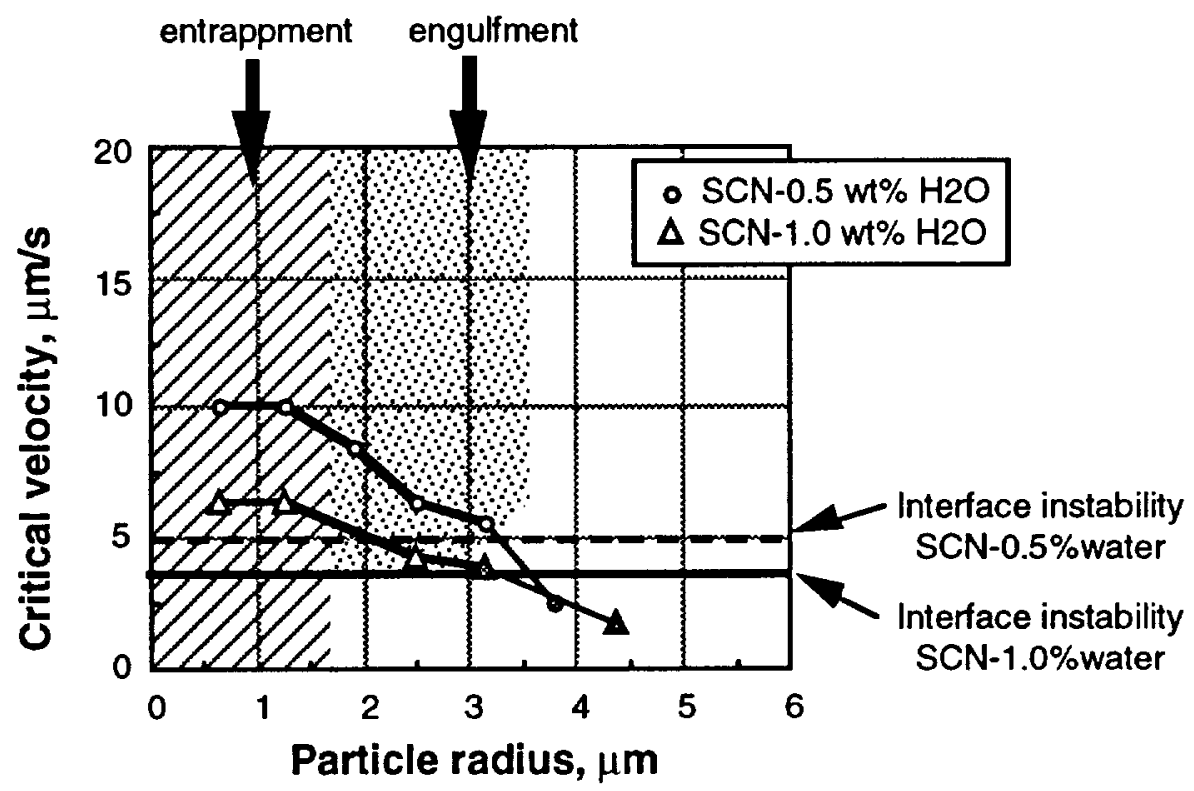

Fig. 4.12. Experimental variation of the critical velocity with particles radii in $S C N /$ water systems $\left(G_{L}=108 \mathrm{~K} / \mathrm{cm}\right)$. Full data points correspond to planar interface.

It can be seen that there is a minor difference as compared with Eq (4.4) for pure $S C N$. This seems to indicate that the solutal field plays a minor role on the critical velocity, within the experimental conditions. Nevertheless, it may be inferred that the solute slightly decreases the critical velocity. Deviations from the law in Eq (4.6) are stronger as particle size and interface stability decrease.

From the well-known constitutional supercooling criterion proposed by Chalmers et al.[4.18] one can obtain the velocity at which interface instability will occur: 


$$
V_{\text {inst }}=-\frac{k D_{L}}{m_{L}(1-k)} \frac{G_{L}}{C_{0}}
$$

where $G_{L}$ is the temperature gradient in the liquid at the interface, $C_{0}$ is the alloy composition, $k$ is equilibrium partition ratio, $D_{L}$ is diffusion coefficient of solute in the liquid, and $\mathrm{mL}$ is the slope of the liquidus line. Thus, as the temperature gradient increases, the velocity for instability increases. Indeed, as shown on Fig. 4.14, as the temperature gradient was increased from 108 to $127 \mathrm{~K} / \mathrm{cm}$, the velocity for instability (represented by full horizontal lines) increased from 3.6 to $4.6 \mu \mathrm{m} / \mathrm{s}$. As a result of this change the deviation of the $V_{c}-r$ curve from the power function occurs at higher velocities. In addition it is seen that for the SCN + $1 \mathrm{wt} \%$ water system an increase in the temperature gradient at the interface from 108 to $127 \mathrm{~K} / \mathrm{cm}$ results in a systematic increase in the critical velocity. This increase seems to be larger for the case of cellular interface (velocities above the limit of stability), than for the case of planar interface. The $V_{c}$ increase with temperature gradient for the planar interface is in agreement with some theoretical predictions. Indeed, the numerical model proposed by Potschke and Rogge [4.9] for systems with impurities suggested the following dependency: $V_{c} \sim G_{L}{ }^{0.5} r^{-1}$. The gradient dependency of $V_{c}$ is due to the fact that the interface curvature is greatly affected by the temperature distribution in the system.

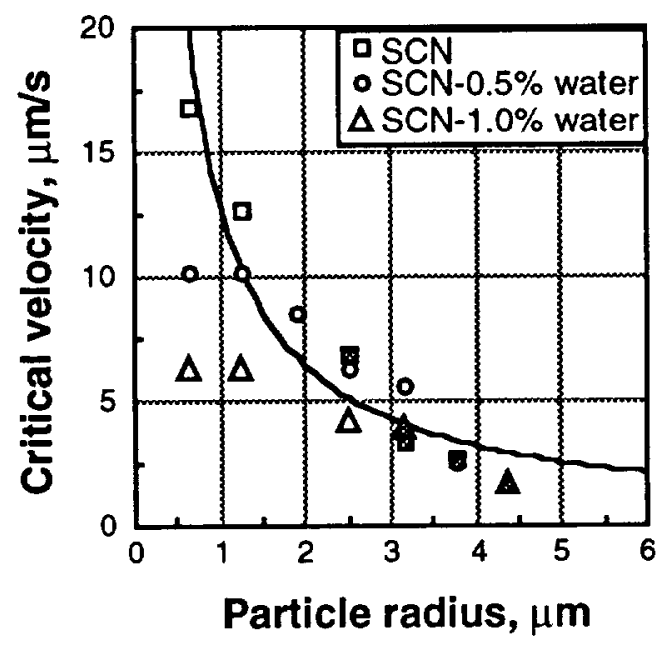

Fig. 13 Correlation between the critical velocity and particle radius in pure $\mathrm{SCN}$ and $\mathrm{SCN}+$ various amounts of water $\left(G_{L}=108 \mathrm{~K} / \mathrm{cm}\right)$.

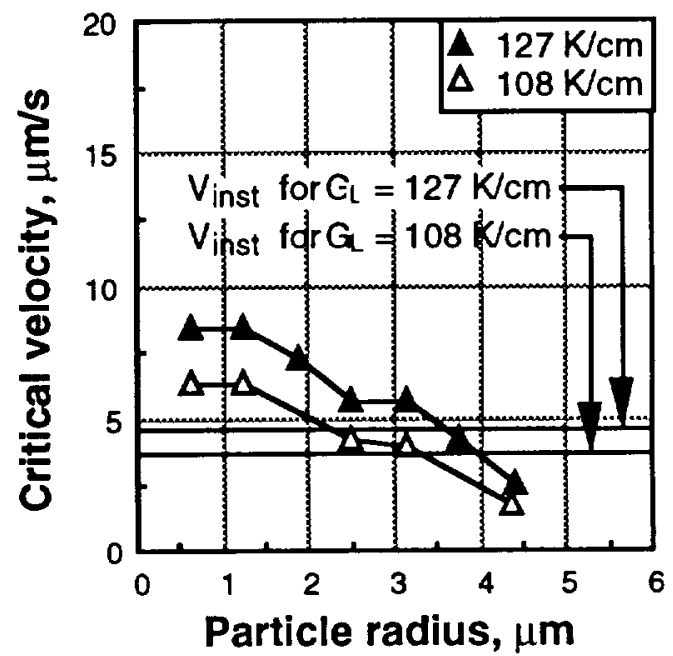

Fig. 14 Experimental variation of the critical velocity with the radius of the particles for different temperature gradient ( $\mathrm{SCN}+1 \%$ water) . 


\subsection{Conclusions}

The role of interface morphology on the critical velocity for particle engulfment in SCN, and its mixtures with water ( 0.5 and $1 \mathrm{wt} \%$ ) was investigated through directional solidification experiments. Polystyrene spheres with radii ranging from 0.5 to $7.5 \mu \mathrm{m}$ were used.

It was found that the experimental correlation between $V_{c}$ and particle radius for planar interface in pure $\mathrm{SCN}$ can be described through the relationship $V_{c}=\frac{13.5}{r}$. This agrees well with theoretical predictions. When all the experimental data for planar interface, including SCN, SCN $+0.5 \%$ water, and $\mathrm{SCN}+1 \%$ water were used the correlation changed to $V_{C}=\frac{12.8}{r}$. This suggests that the solute slightly decreases the critical velocity. When the data for cellular interfaces were also included in the analysis, the correlation became $V_{c}=\frac{12.1}{r}$. This means that the break down of the interface further decreased the critical velocity. In fact, as the interface became unstable in the SCN + water systems, the $V_{c}-r$ correlation strongly deviated from the $V_{c}=$ cons./ $r$ law, which was found to describe well all experiments with planar interface.

It was also found that the critical velocity increased with the temperature gradient for both planar and cellular interfaces. No evidence of depression formation at the liquid/solid interface was observed, although the thermal conductivity of the particle was smaller than that of the matrix. This apparent discrepancy with the theory is attributed to the fact that some models ignored the role of the latent heat evolved at the interface.

\subsection{Appendix 1: Numerical Values Used in Calculations}

Viscosity of succinonitrile $\mathrm{h}=2.59 \times 10^{-3} \mathrm{Kg} \mathrm{m}^{-1} \mathrm{~s}^{-1}$ [4.19]

Atomic distance in succinonitrile, $a_{o}=5.9 \times 10^{-10} \mathrm{~m}$

Thermal conductivity:

for succinonitrile: $\mathrm{K}_{\mathrm{L}}=0.223 \mathrm{Wm}^{-1} \mathrm{~K}^{-1}[4.19]$

for polystyrene: $\mathrm{K}_{\mathrm{P}}=0.0794 \mathrm{Wm}^{-1} \mathrm{~K}^{-1}[4.19]$ 


\section{List of Symbols Chapter 4}

\begin{tabular}{|c|c|}
\hline $\begin{array}{l}C_{0} \quad \text { alloy composition } \\
D_{L} \text { diffusion coefficient of solute in } \\
\text { the liquid } \\
G_{L} \text { temperature gradient in the } \\
\text { liquid at the interface } \\
K_{L} \text { thermal conductivity (matrix) } \\
K_{p} \text { thermal conductivity (particle) } \\
T_{s} \text { soak temperature } \\
V \quad \text { interface velocity } \\
V_{\text {inst }} \quad \text { velocity at which interface } \\
\text { instability will occur } \\
V_{c} \quad \text { critical velocity } \\
V_{e} \quad \text { equilibrium velocity }\end{array}$ & $\begin{array}{ll}a_{0} & \text { atomic distance } \\
d & \text { separation between the particle } \\
\text { and the interface } \\
d_{c} \quad \text { critical distance between the } \\
\text { particle and the interface } \\
g \quad \text { acceleration due to gravity } \\
k \quad \text { equilibrium partition ratio } \\
\mathrm{mL}_{\mathrm{L}} \quad \text { slope of liquids line } \\
\mathrm{r} & \text { particle radius } \\
\mu & \text { thermal conductivity ratio } \\
\mathrm{h} & \text { liquid viscosity } \\
\Delta \rho & \text { density difference } \\
\Delta \sigma_{0} & \text { interfacial energy difference } \\
\end{array}$ \\
\hline
\end{tabular}

Subscripts

L liquid

P particle

\section{References Chapter 4}

4.1. D.R. Uhlmann, B. Chalmers, and K.A. Jackson: J. Appl. Phys., 1964, vol. 35 (10), pp. 385-88.

4.2. O.P. Fedorov: J. Cryst. Growth, 1990, vol. 102, pp. 857-61.

4.3. S.N. Omenyi and A.W. Neumann: J. Appl. Phys. 1976, vol. 47 (9), pp.3956-62.

4.4. A.M. Zubko, V.G. Lobanov, and V.V. Nikonova: Sov. Phys. Crystallogr., 1973, vol. 18 (2), pp, 239-41.

4.5. J. Cisse and G.F. Bolling: J. Cryst. Growth, 1971, vol. 11, pp. 25-28.

4.6. D.M. Stefanescu, B.K. Dhindaw, S.A. Kacar, and A. Moitra: Metall. Trans. A, 1988, vol. 19A, pp. 2847-55.

4.7. D.M. Stefanescu, A. Moitra, A.S. Kacar, and B.K. Dhindaw: Metall. Trans. A, 1990, vol. 21A, pp. 231-39.

4.8. G.F. Bolling and J.A. Cisse: J. Cryst. Growth, 1971, vol. 10, pp. 56-66.

4.9. J. Potschke and V. Rogge: J. Cryst. Growth, 1989, vol. 94, pp.726-38.

4.10. R. Sasikumar, T.R. Ramamohan, and B.C. Pai: Acta Metall., 1989, vol. 37 (7), pp. 2085-91. 
4.11. A.A. Chernov, D.E. Temkin, and A.M. Mel'nikova: Sov. Phys. Crystallogr., 1976, vol. 21 (4), pp. 369-73.

4.12. D. Shangguan, S. Ahuja and D.M. Stefanescu: Metall. Trans. A, 1992, vol. 23A, pp. 669-680.

4.13. D.M. Stefanescu, B.K. Dhindaw, A.S. Kacar, and A. Moitra: Metall. Trans. A, 1988, vol. 19A, pp. 2847-2855.

4.14. J.A. Sekhar and R. Trivedi: in Solidification of Metal Matrix composites, P. Rohatgi, editor, Proceedings of a Conference, Indianapolis, 1989, pp. 39-50.

4.15. S. Ahuja: PhD Dissertation, The University of Alabama, Tuscaloosa, 1992.

4.16. A. M. Zubko, V. G. Lobanov and V. V. Nikonova: Soviet Physics Crystallography, 1973, vol. 18, pp. 239-241.

4.17. Ch. Korber, G. Rau, M.D. Cosman, and E.G. Cravalho: J. Cryst. Growth, 1985, vol. 72, pp. 649-62.

4.18. J.W. Rutter and B. Chalmers: Can. J. Phys., 1953, vol. 3, p.15.

4.19. J. A. Dean: Lange's Handbook of Chemistry, 14th, Mc Graw - Hill, 1992. 


\section{TASK T1.1}

The objective of Task 1 is to further improve the existing analytical model for pushing/engulfment of particles during solidification of metallic alloys with planar solid/liquid interfaces. The scope of sub task T 1.1 is to develop a model that includes an analysis of both the thermal and force fields.

An enhanced analytical steady state model for predicting the critical velocity of engulfment of an insoluble particle by the advancing melt interface was developed. This model couples the thermal and force fields acting on an insoluble particle at the liquid -- solid interface. Equations that determine the equilibrium distance for the force and thermal fields as a function of velocity were derived. The solution of these equations gives a unique value for the critical velocity of engulfment, and for the critical particle -- interface distance during pushing. The role of the thermal gradient, of particle and matrix thermal conductivities, and of the interface force is discussed. The model is validated with experimental results for succinonitrile and $\mathrm{SiC}$ or polystyrene particles. Literature data on the critical velocity for aluminum based composites containing alumina or SiC particles, and for the water -- tungsten systems also compare favorably with calculated results. The model is applicable to particulate metal matrix composites.

\subsection{Background}

One of the processing methods for particulate reinforced metal matrix composites (MMC) consists of mechanical mixing of particles in the liquid alloy. In the solidification interval the structure of such a composite includes three phases: liquid alloy, solid particulate reinforcements, and solidified alloy grains. The as-cast microstructure is the result of solidification kinetics that governs the growth of the equiaxed grains, and of particle/grain interface interaction that governs pushing or engulfment of particles into the growing grains. As a result of these two simultaneously occurring phenomena, the reinforcing particulates can be distributed intergranular, intragranular or mixed at the end of solidification. Since this distribution determines the properties of the composite its prediction is of considerable interest. 
In a first approximation the issue of particle/grain interaction can be treated in a similar manner as the particle/planar interface interaction, assuming that the grain is large as compared with the particle. It is generally accepted that when a moving solidification front intercepts an insoluble particle, it can either push it or engulf it. In the case of engulfment the solid grows around the particle. It has been demonstrated experimentally [5.1] that, at a given critical velocity, fixed for the system, a transition from particle pushing to particle engulfment occurs. If the solidification interface becomes unstable resulting in formation of dendrites or equiaxed grains, two or more solidification fronts can converge on the particle. Even if the particle is not engulfed by one of the fronts, it will be eventually entrapped in the solid at the end of the local solidification. The problem is of rather general interest to such problems as particle distribution in ceramic particulate reinforced metal matrix composites, growth of monotectics, inclusion segregation in castings, frost heave in soils, and emulsion of organic cell suspensions in ice in cryobiology. More recently a novel theoretical approach to the mechanism of heterogeneous nucleation of pores in metallic systems has been developed on the basis of the particle pushing theory [5.2].

The interaction between a particle and an advancing planar liquid/solid interface has been discussed by a number of authors [5.3-5.6]. An analytical model has been proposed by two of the authors of this paper [5.7] (referred to as the SDKM model), and further refined recently (the SAS model) [5.8].

This last model involved the following analysis: (1) solving the temperature field for the particle/matrix configuration in order to calculate the shape of the solid/liquid interface in the vicinity of the particle; this is needed because the interface will locally deviate from planarity if the thermal conductivity of the particle, $K_{P}$, differs from that of the matrix, $K_{L}$, while a macroscopically planar interface may still be maintained; (2) solving the force field acting on the particle; (3) establishing the critical condition for the pushing/engulfment transition. The solidification latent heat was ignored in the solution of the thermal field. The model considers the behavior of a particle in front of a macroscopically planar solid/liquid interface; however, local deviations from planarity are allowed (Fig. 5.1). 


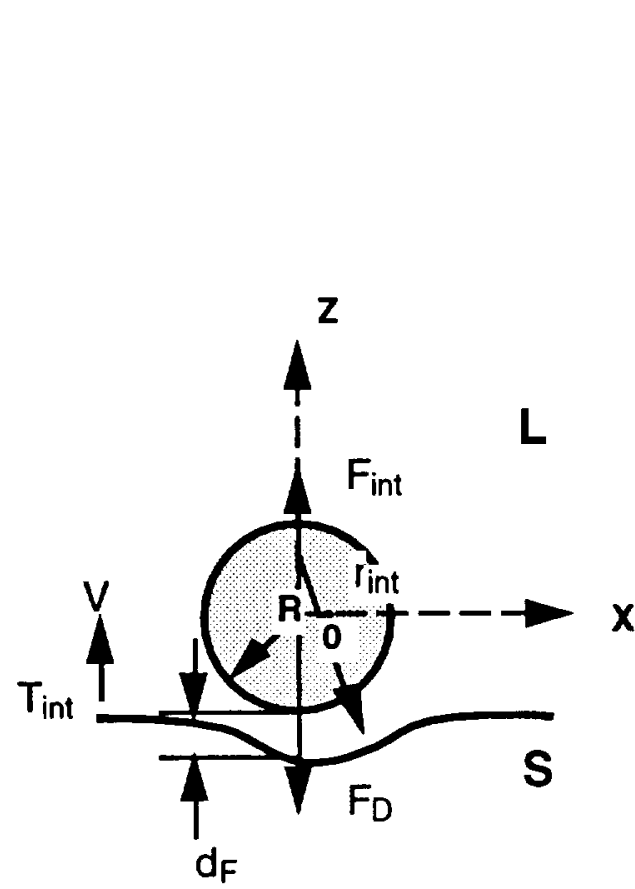

a)

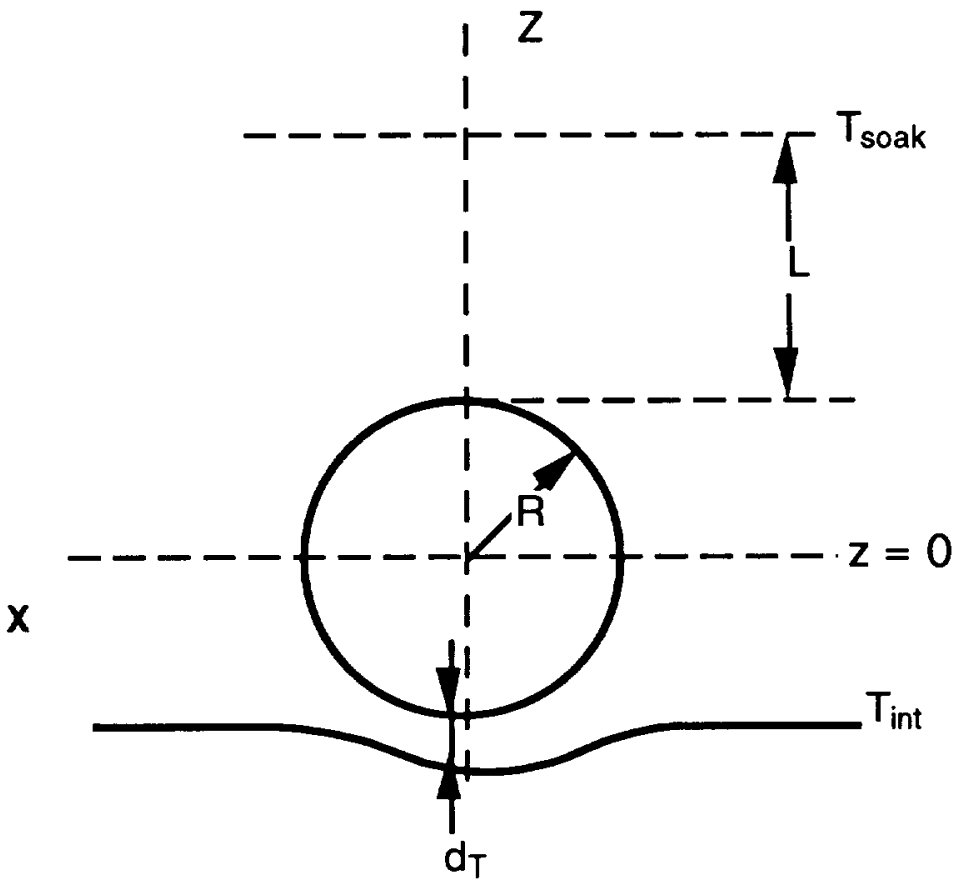

b)

Fig. 5.1 Schematic drawing showing (a) forces acting on the particle and coordinate system for calculation of the force equilibrium distance, $d_{F}$, and $(b)$ the coordinate system for calculation of the thermal equilibrium distance, $d_{T}$, for

$$
\mathrm{K}_{\mathrm{p}} / \mathrm{K}_{\mathrm{m}}>1 \text {. }
$$

The force field acting on the particle was analyzed based on UhImann et al. model [5.3]. This model assumes that the interface energy changes with the particle/interface distance as shown in Fig. 5.2.

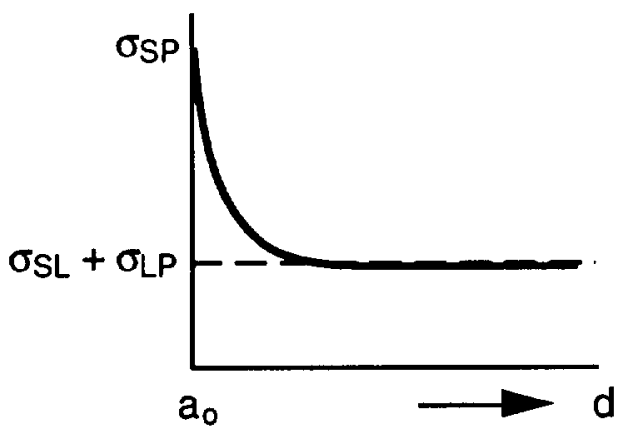

Fig. 5.2 Variation of interface energy with particle/interface distance [5.3]. 
If one writes:

$$
\sigma_{o}=\sigma_{s p}-\left(\sigma_{s \mid}+\sigma_{\mid p}\right)
$$

then, the interface energy change as the particle approaches the interface can be written as:

$$
\Delta \sigma=\Delta \sigma_{0}\left(\frac{a_{0}}{a_{0}+d}\right)^{n}
$$

The subscripts $s, 1$, and $p$ stand for solid, liquid and particle, respectively. According to Uhlmann et al. [5.3] $n$ may have values of the order of 4 or 5 . It must be noted though that, if Coulombic forces are considered, $n=2$, while for Van der Waals forces $n=7$. Coulombic forces are active over distances of the order of $10^{-8} \mathrm{~m}$, while Van der Waals forces are effective at distances of the order of 10$10 \mathrm{~m}$. Unfortunately, the actual nature of the interaction is not known. Overlapping interactions may result in any values of $n$, including $n<2$. Accordingly, it will be assumed that values of $n$ between 1 and 7 are conceivable.

From the force balance on the particle (the drag force $F_{D}$ and the interaction or repulsive force $F_{\text {int }}$ ), and neglecting gravity effects (which is a good approximation during horizontal directional solidification), the following equation was obtained for the equilibrium solidification (interface) velocity for the pushing/engulfment transition:

$$
v_{e}=\frac{\Delta \sigma_{0} d_{F}}{3 \eta \mu R}\left(\frac{a_{0}}{a_{0}+d_{F}}\right)^{n}
$$

where $D s_{o}$ is the interface energy at minimum separation, $d_{F}$ is the steady state particle/interface distance for the force field, $h$ is the liquid viscosity, $m=K_{P} / K_{L}$ is the thermal conductivity ratio, $R$ is the radius of the particle, and $a_{0}$ is the interatomic distance. A detailed discussion of the nature of the forces acting on the particle, as well as the mathematical derivation of Eq (5.3) was provided in Ref. [5.8].

For $n=2$, equation (5.3) gives two solutions for $d_{F}$, for a given interface velocity, $V_{e}$. In order to remove this uncertainty, in the SAS model it was assumed that the initial velocity corresponds to the unique value of $d_{F}$, which is obtained through maximization of $V_{e}$ with respect to $d_{F}$. The physics behind this 
maximization can be understood from Fig. 5.3, which shows the variation of $V_{e}$ versus $\mathrm{d}$ calculated for an Al-SiC system. As the interface velocity is increased the equilibrium distance at steady state decreases until a critical distance is reached for the maximum equilibrium velocity, which is considered to be the critical velocity. This is done since a further increase in velocity does not have any solution on the basis of the mathematics used in SAS-92. It is thus implied that at interface velocity higher than $V_{C}$, steady state conditions cease to exist, and the particle is engulfed. It must be noted that selecting the distance corresponding to the maximum equilibrium velocity to be the critical distance is only an assumption. To find a unique solution for Eq.(5.3) another equation is needed. The quest for an unique solution was thus the goal of the present research.

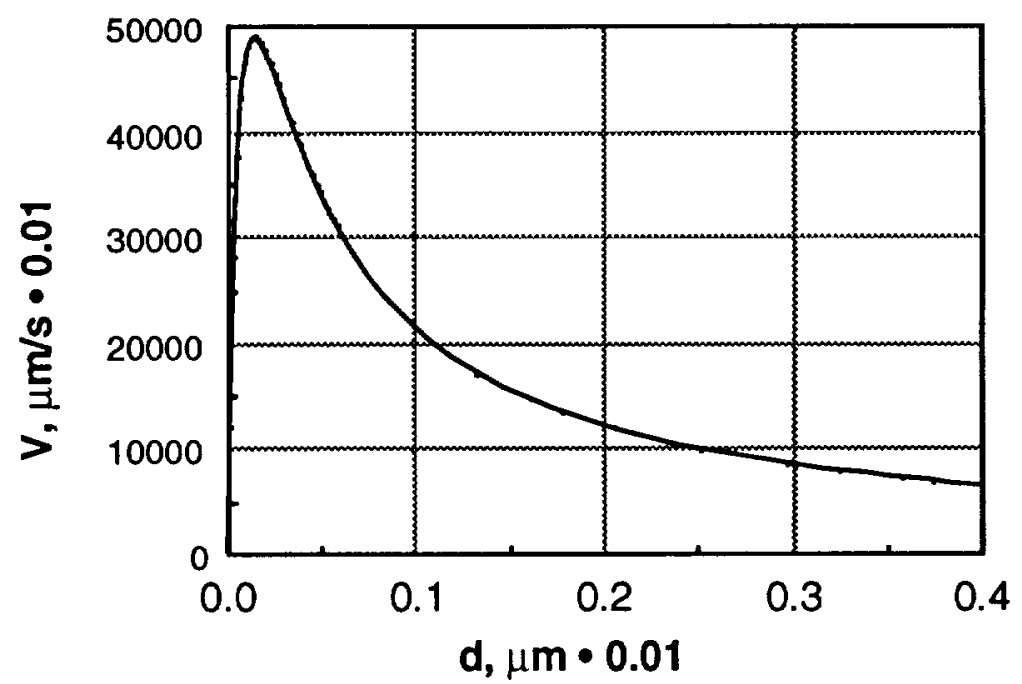

Fig. 3 Calculated correlation between the equilibrium steady state interface velocity and particle - interface distance for an $\mathrm{Al}$ - SiC system

\subsection{Theoretical Work}

\section{A. Analysis of the Force Field (SDKM/SAS Models)}

Eq.(5.3) was plotted in Fig. 5. 4 for an $\mathrm{Al} / \mathrm{SiC}$ system for various values of n. Particle radius was considered to be $50 \mathrm{~mm}$, and the other constants used for calculation are given in Table 5.1 in the Appendix of chapter 5 . It can be seen that, with the exception of the case $n=1$, for each velocity there are two solutions 
for $d_{F}$. Obviously, only those solutions giving $d_{F}>a_{0}$ can be accepted, since $d_{F}<$ $a_{o}$ means particle engulfment. Thus, at steady state, for each interface velocity a minimum equilibrium distance between the particle and the interface will exist. In other words, as the velocity increases from a value smaller than the critical velocity, $V_{c r}$, the particle -- interface distance decreases to maintain steady state. If no other effects are considered, this distance can decrease until the maximum of the $V . . d_{F}$ curve is reached. If the velocity increases above the maximum value for $d_{F}$, steady state does no longer exist, and engulfment occurs. In the SDKM model [5.7] it was arbitrarily assumed that $d_{c r}=a_{o}$. In the SAS model [5.8] the maximum of the $\mathrm{V}-\mathrm{d}_{\mathrm{F}}$ curve was considered to be the critical distance, and the corresponding velocity -- the critical velocity. For $n=2$, similar equations were thus derived for $V_{c r}$ for both models.

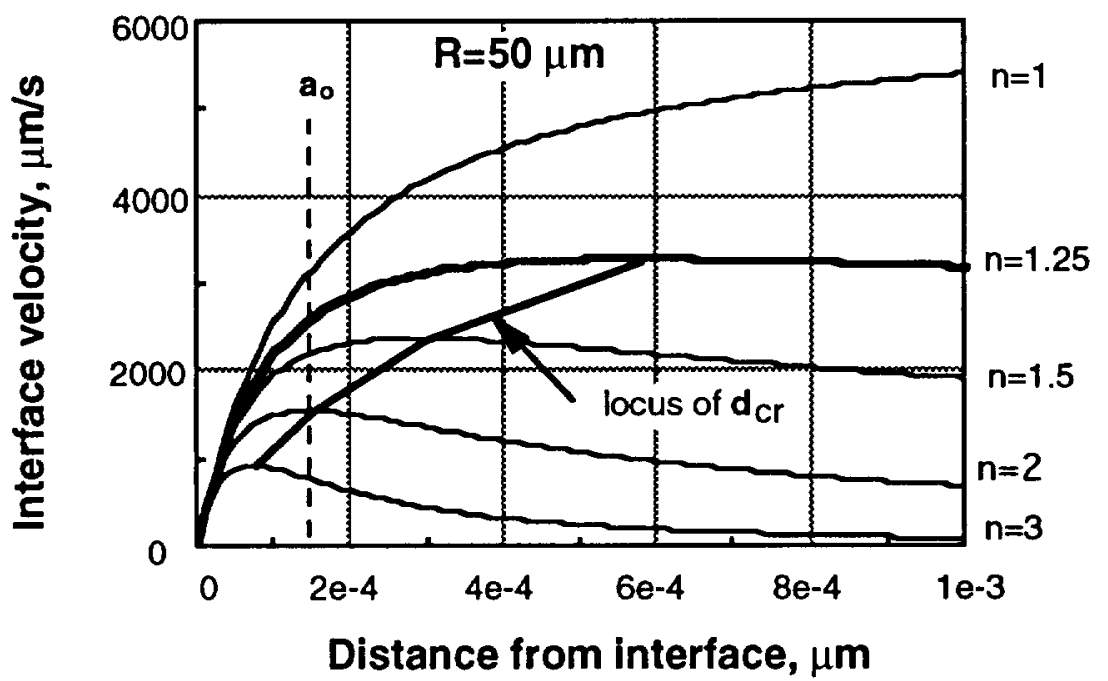

Fig. 5.4 Influence of assumption made for $n$ in Eq.(5.1) on the critical distance obtained through maximization of the equation for $\mathrm{Al} / \mathrm{SiC}$ composite.

The locus of $d_{c r}$ as a function of $n$ is shown in Fig. 5.4. It can be seen that values for $n \geq 3$ are unacceptable, since critical distances smaller than the atomic distance are predicted.

In the SAS model mainly the force field was used to evaluate the critical velocity and the critical distance. The thermal field was only considered in the 
calculation of the drag force, since it changes the shape of the interface. Nevertheless, its role in the establishment of the particle -- interface equilibrium distance was neglected.

\section{B. Analysis of the Thermal Field}

To find a unique solution to Eq.(5.3), that is to uniquely determine the critical velocity and the critical distance, an additional correlation between $V$ and $d$ is required. This correlation can be obtained if it is assumed that at steady state the thermal field will also impose an equilibrium distance for a given $\mathrm{V}$. This is the thermal equilibrium distance, $d_{T}$. As shown in Fig. 5.1, the interface will bend in the vicinity of the particle to accommodate the change in heat flux resulting from the $\mathrm{K}_{\mathrm{P}} / \mathrm{K}_{\mathrm{L}}$ difference. The change in the radius of curvature of the interface, and therefore in the particle -- interface distance, will continue until equilibrium is reached.

The governing equation is the time independent form of the heat conduction equation with moving boundaries. A two- or three-dimensional solution will involve boundary conditions that are characteristic for the particular experimental setup used. Thus, only a one dimensional solution will be attempted at this point. The governing equations in Cartesian coordinates are:

for the particle: $\quad \frac{\partial^{2} T}{\partial z^{2}}=0$

for the matrix: $\quad \frac{\partial^{2} T}{\partial z^{2}}-\frac{V}{\alpha} \frac{\partial T}{\partial z}=0$

where $T$ is the temperature, $V$ is the solidification velocity, and $a$ is the thermal diffusivity. It was assumed that the thermal conductivities of the solid and liquid are identical and are different from that of the particle. Heat transfer in the $x$ and $y$ directions was ignored. The temperature gradient in the melt, far away from the particle (see Fig. 5.1) is constant. The origin is in the center of the particle. The following boundary conditions were used:

$B C 1: K_{S} G_{S}-K_{L} G_{L}^{\prime}=\Delta H V$ 
BC2: At $z=0, \quad T_{p}=T_{\text {soak }}-G_{L} L-\frac{G_{L}}{\mu} R$ where the temperature gradient in the liquid is defined as $G_{L}=\frac{T_{\text {soak }}-T_{\text {int }}}{L+2 R+d_{T}}$

and since $d_{T} \ll R$, can be approximated to: $G_{L}=\frac{T_{\text {soak }}-T_{\text {int }}}{L+2 R}$

BC3: $\left(\frac{\partial T_{m}}{\partial z}\right)_{z=-R}=\mu\left(\frac{\partial T_{p}}{\partial z}\right)_{z=-R}$

BC4: $\left(\mathrm{T}_{\mathrm{m}}\right)_{z=-\mathrm{R}}=\left(\mathrm{T}_{\mathrm{p}}\right)_{z=-\mathrm{R}}$

where, $\mathrm{K}_{\mathrm{S}}, \mathrm{K}_{\mathrm{L}}$ are the thermal conductivities of the solid and liquid, respectively, $\mathrm{G}_{\mathrm{S}}$ is the temperature gradient in the solid, $\mathrm{G}_{\mathrm{L}}^{\prime}$ is the temperature gradient in the liquid film between the particle and the interface, $G_{L}$ is the temperature gradient in the liquid, $T_{\text {soak }}, T_{i n t}, T_{m}$, and $T_{p}$ are the soak, interface, matrix, and particle temperatures, respectively, $L$ is the length of the temperature field over which the gradient is measured, and $\Delta \mathrm{H}$ is the latent heat of fusion. The soak or the set temperature is measured at a distance $L$ from the solid/liquid interface. The solutions of Eqs. (5.4) and (5.5) are as follows:

$$
T_{m}=A+B \exp \left(\frac{V}{\alpha_{m}} z\right)
$$

and

$$
T_{p}=C+D z
$$

The constants A, B, C, and D are obtained by using the boundary conditions, Eqs. (5.6) through (5.9) in the solutions, Eqs. (5.10) and (5.11). They are:

$$
\begin{aligned}
& A=T_{\text {soak }}-G_{L} L-\frac{G_{L} R}{\mu}-\left[\frac{\alpha_{m}}{V}+\frac{R}{\mu}\right]\left(\frac{K_{S} G_{S}-L V}{K_{L}}\right) \exp \left[\frac{V d_{T}}{\alpha_{m}}\right] \\
& B=\left(\frac{\alpha_{m}}{V}\right)\left(\frac{K_{S} G_{S}-L V}{K_{L}}\right) \exp \left[\frac{V}{\alpha_{m}}\left(R+d_{T}\right)\right] \\
& C=T_{\text {soak }}-G_{L} L-\frac{G_{L}}{\mu} R
\end{aligned}
$$




$$
D=\left(\frac{K_{S} G_{S}-L V}{\mu K_{L}}\right) \exp \left[\frac{V d_{T}}{\alpha_{m}}\right]
$$

Substituting the values of the constants $A$ and $B$ in Eq. (5.10) the final solution for the temperature of the matrix (liquid) at any position along the $z$ axis is calculated to be:

$$
\begin{gathered}
T_{m}=T_{\text {soak }}-G_{L} L-\frac{G_{L} R}{\mu}-\left[\frac{\alpha_{m}}{V}+\frac{R}{\mu}\right]\left(\frac{K_{S} G_{S}-L V}{K_{L}}\right) \exp \left[\frac{V d_{T}}{\alpha_{m}}\right] \\
+\left(\frac{\alpha_{m}}{V}\right)\left(\frac{K_{S} G_{S}-L V}{K_{L}}\right) \exp \left[\frac{V}{\alpha_{m}}\left(R+d_{T}+z\right)\right]
\end{gathered}
$$

To calculate the thermal equilibrium distance, it is now necessary to obtain a particular solution of Eq. (5.16) for a position on the solid/liquid interface. That is for:

$$
z=-\left(R+d_{T}\right) \quad \text { where } \quad T_{m}=T_{\text {int }}
$$

Substituting in Eq.(5.16), the following solution is obtained for the thermal equilibrium particle - interface distance:

$$
d_{T}=\frac{\alpha_{m}}{V} \ln \left\{\frac{\left(T_{\text {soak }}-T_{\text {int }}\right)-G_{L} L-\frac{G_{L} R}{\mu}+\left(\frac{\alpha_{m}}{V}\right)\left(\frac{K_{S} G_{S}-L V}{K_{L}}\right)}{\left(\frac{\alpha_{m}}{V}+\frac{R}{\mu}\right)\left(\frac{K_{S} G_{S}-L V}{K_{L}}\right)}\right\}
$$

Substituting the value of $\left(\mathrm{T}_{\text {soak }}-\mathrm{T}_{\text {int }}\right)$ from Eq.(5.7), Eq.(5.17) can be simplified to:

$$
d_{T}=\frac{\alpha_{m}}{V} \ln \left\{\frac{G_{L} R\left(2-\frac{1}{\mu}\right)+\left(\frac{\alpha_{m}}{V}\right)\left(\frac{K_{S} G_{S}-L V}{K_{L}}\right)}{\left(\frac{\alpha_{m}}{V}+\frac{R}{\mu}\right)\left(\frac{K_{S} G_{S}-L V}{K_{L}}\right)}\right\}
$$

\section{Coupled force and thermal fields}

It is assumed that the critical distance is that one at which the particle is in equilibrium in both the force and the thermal fields. The force field and the thermal field must thus be coupled, that is: 


$$
d_{F}=d_{T}
$$

To couple the force field and the thermal field Eqs.(5.3), (5.18) and (5.19) must be solved simultaneously, graphically, analytically, or numerically. They are plotted in Fig. 5.5 for a succinonitrile/SiCp system for particles of radius $18 \mathrm{~mm}$ and different values of $n$. The data used for calculation are given in Table 5.1 (Appendix chapter 5). $a_{0}$ was taken as the molecular length of succinonitrile. The intersections of the two equations give unique values for both the critical velocity and the critical distance. For example, for $n=1.5$ a critical velocity of $4 \mathrm{~mm} / \mathrm{s}$ and a critical distance of $8.74 \mathrm{~mm}$ are calculated for the $4 \mathrm{~mm}$ radius particle. It can be also noticed that while the equilibrium distance is practically unaffected by the value taken for $n$, on the contrary, the critical velocity is highly dependent on $n$.

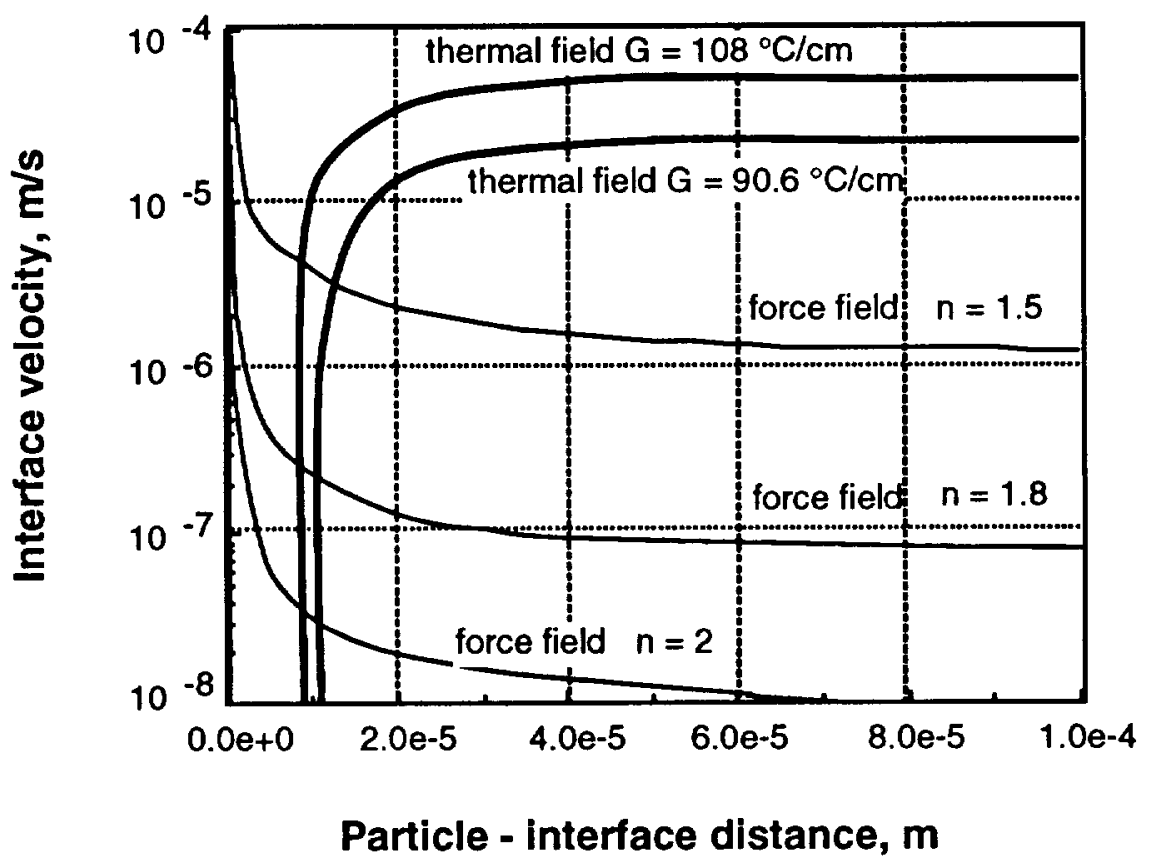

Fig. 5.5 Influence of assumption made for $\mathrm{n}$ in Eq.(5.2) on the calculated critical velocity for the succinonitrile/SiCp system. Particle radius is $4 \mu \mathrm{m}$.

\subsection{Experimental Work}

To validate the proposed model a number of experiments were conducted on transparent organic material (succinonitrile) and various particles. The 
experimental setup for directional solidification of transparent matrix systems is shown schematically in Fig. 5.6. A complete description of the experimental apparatus is given in Ref. [5.9]. Horizontal solidification was preferred to eliminate the role of the gravity force on the particle -- interface interaction.

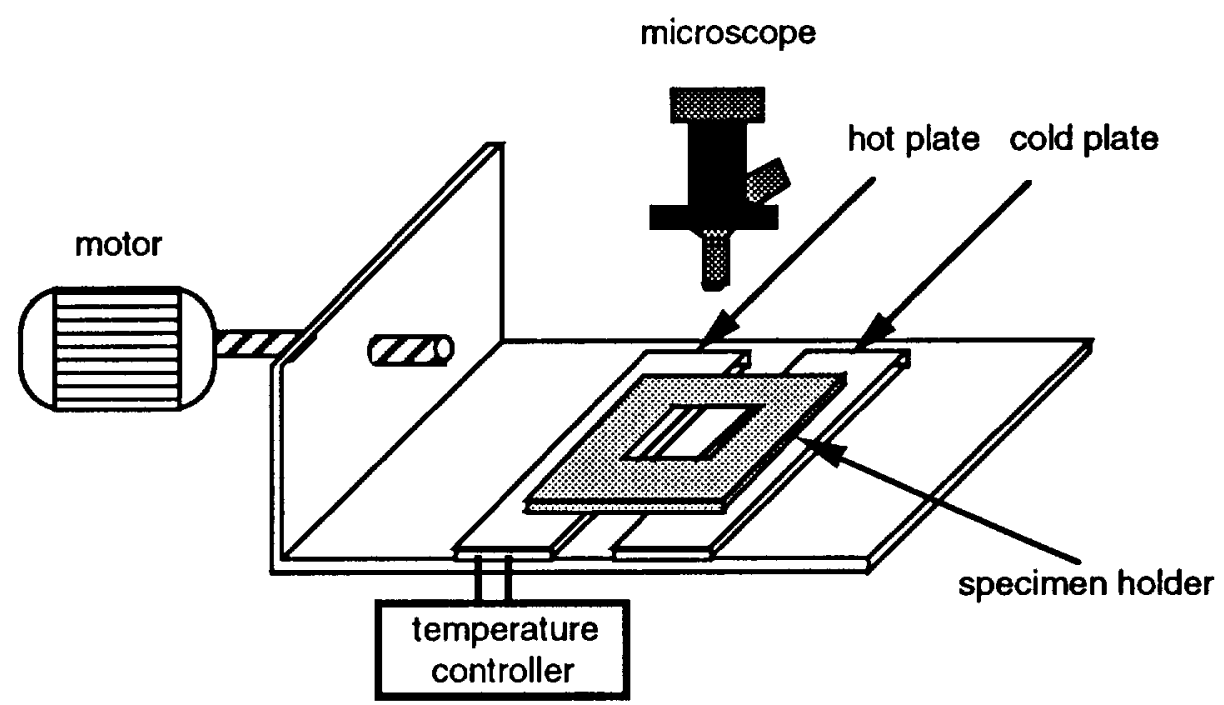

Fig. 5.6 Temperature gradient stage for directional solidification of transparent matrix materials.

Specimens were prepared by drawing a previously prepared mixture of particles and succinonitrile between two quartz slides. The slide was placed between the heater and the cooler. In this way a temperature gradient was imposed over the slide. The temperature gradient at the solid -- liquid interface was changed either by decreasing the distance between the heater and the cooler, or by varying the temperature of the heater. The solidification velocity was controlled through the translation velocity of the slide imposed by the motor.

The matrix in all the experiments consisted of succinonitrile. Two kinds of particles were chosen for this study: polystyrene particles of diameters varying from 3 to $80 \mu \mathrm{m}$ and $\mathrm{SiC}$ particles 8 and $36 \mu \mathrm{m}$ in size. Polystyrene has a lower thermal conductivity than succinonitrile, while $\mathrm{SiC}$ has a higher conductivity.

The interface velocity was set at $3.68 \mathrm{~mm} / \mathrm{s}$ and the temperature gradient was measured in the vicinity of the melt interface. Typical measured data required in Eq.(5.17) are given in Table 5.I.

In the experiments with $\mathrm{SiC}$ particles dispersed in succinonitrile (SCN) it was found out that at a solidification velocity of $9.2 \mathrm{~mm} / \mathrm{s}$, a large particle $(R=18$ 
$\mathrm{mm}$ ) was engulfed (Fig. 5.7,a), while a small particle $(R=4 \mathrm{~mm}$ ) was pushed. When the solidification velocity was increased to $21 \mathrm{~mm} / \mathrm{s}$, the small particle induced the formation of a trough on the interface, and was eventually engulfed as the borders of the trough closed behind it (Fig. 5.7,b).

Table 5.I Experimental data used in the calculation of the thermal equilibrium distance.

\begin{tabular}{|c|c|c|c|c|}
\hline Soak Temperature, $\mathrm{T}_{\mathbf{S}}\left({ }^{\circ} \mathrm{C}\right)$ & 64 & 71 & 75 & 80 \\
\hline Temp. Gradient, $\mathrm{GL}_{\mathrm{L}}\left({ }^{\circ} \mathrm{C} / \mathrm{m}\right)$ & $4.96 \cdot 10^{3}$ & $6.24 \cdot 10^{3}$ & $9.06 \cdot 10^{3}$ & $1.08 \cdot 10^{4}$ \\
\hline
\end{tabular}

A similar experiment was run using $75 \mathrm{~mm}$ diameter polystyrene micro spheres dispersed in SCN. The thermal conductivity of polystyrene $\left(0.0794 \mathrm{~W} \mathrm{~m}^{-}\right.$ $1 \mathrm{~K}^{-1}$ ) is lower than that of SCN. Under a solidification velocity of $2.5 \mathrm{~mm} / \mathrm{s}$ the particle was engulfed. Again, trough formation occurred on the melt interface.
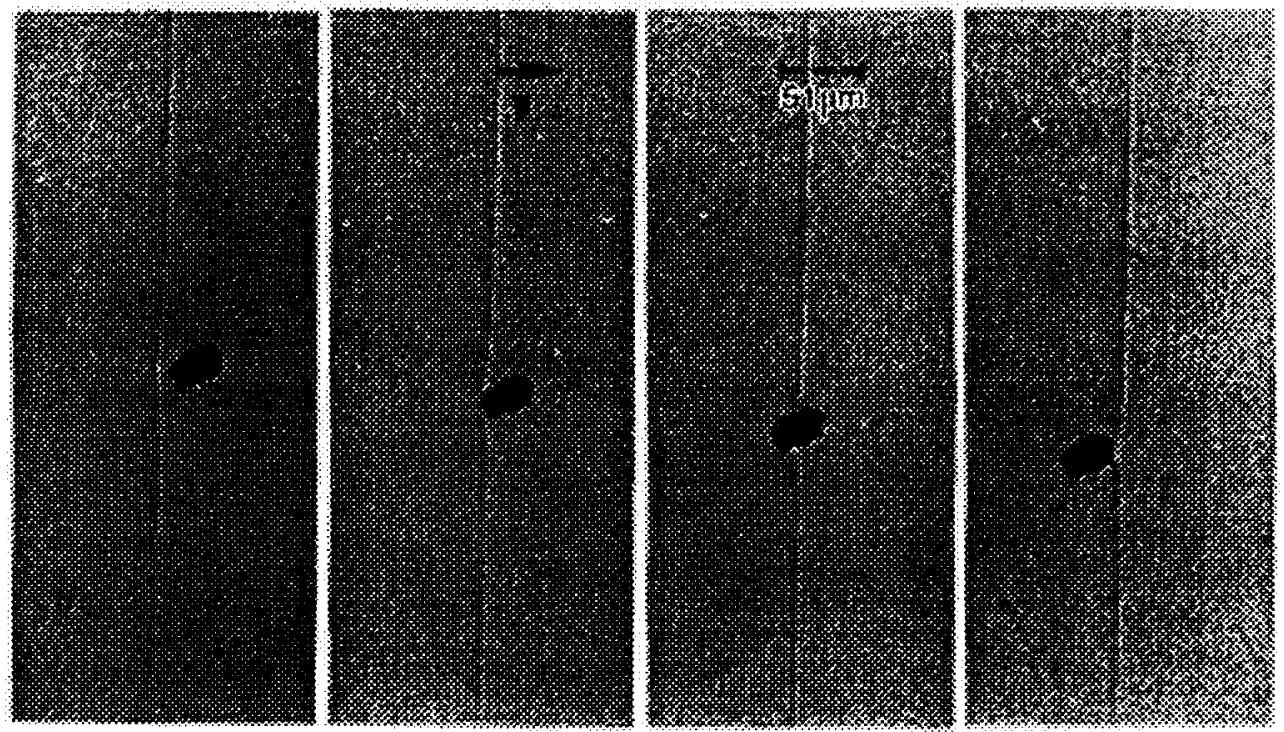

a) large particle (small $\left.V_{c r}\right) ; V_{\text {growth }}=9.2 \mathrm{~mm} / \mathrm{s}$, time step $3 \mathrm{~s}, R=18 \mathrm{~mm}$ 

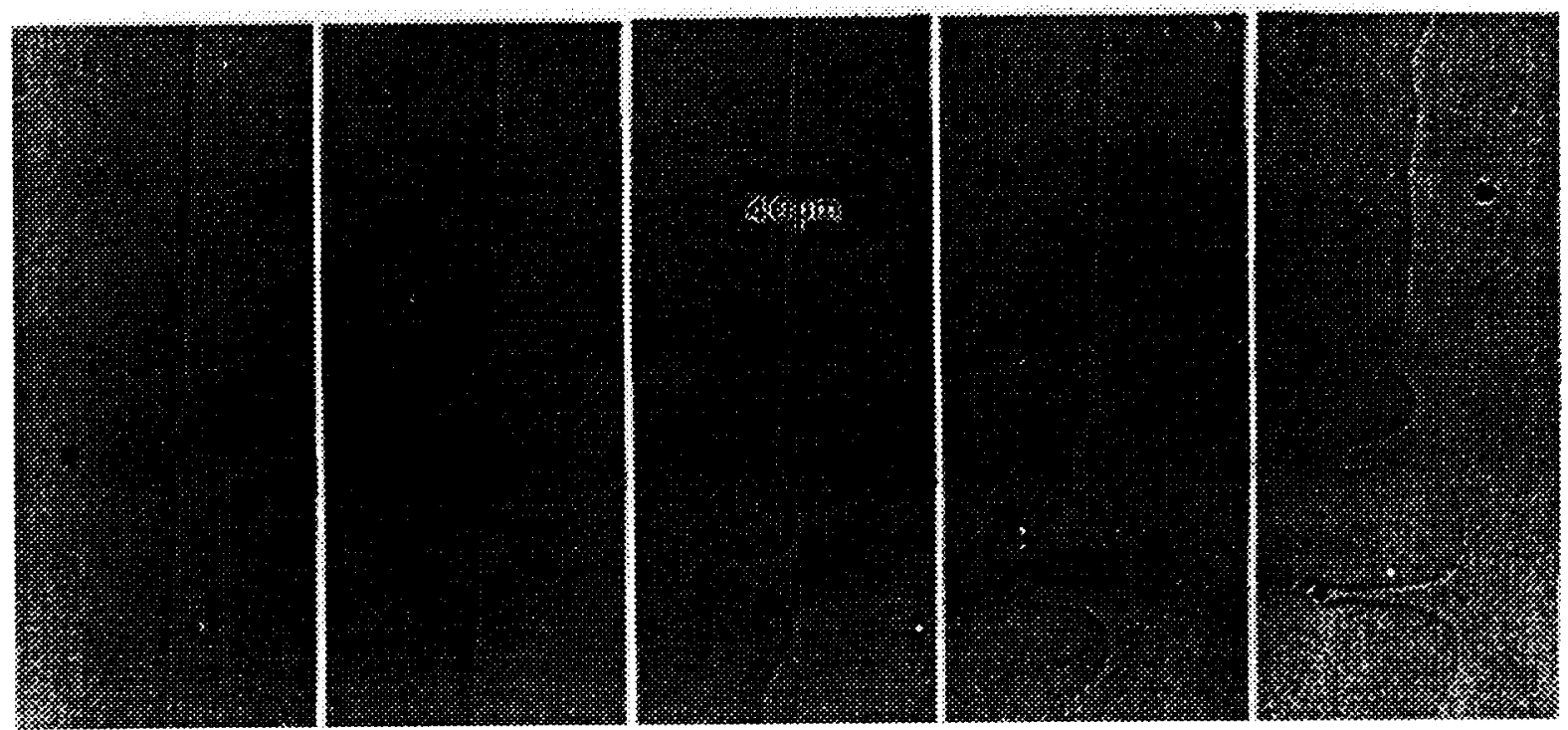

b) small particle (large $V_{c r}$ ); $V_{\text {growth }}$ increased from 9.2 to $21 \mathrm{~mm} / \mathrm{s}$, time step $4 \mathrm{~s}$, $\mathrm{R}=4 \mathrm{~mm}$

Fig. 5.7 Experimental observation of engulfment of $\mathrm{SiC}$ particles by the $\mathrm{L} S$ interface in succinonitrile.

\subsection{Discussion}

Since the value of the $\mathrm{Kp} / \mathrm{Km}$ ratio influences not only the shape of the interface but also the particle -- interface interaction, it is reasonable to divide the discussion in two parts, according to the value of the ratio.

\section{A. Case 1: $\mathrm{Kp} / \mathrm{Km}>1$}

The physics behind Eqs. (5.3) and (5.18) and Fig. 5.5 may be understood as follows. Consider a particle in the vicinity of the interface moving at a velocity $V>V_{c r}$ (Fig. 5.8). The force field will allow the particle to approach the interface up to a distance $d_{F}<d_{c r}$ and $d_{F}<d_{T}$ (Fig. 5.9,a). Consequently, the thermal field will "push" the interface trying to reestablish the equilibrium distance $\mathrm{d}_{\mathrm{T}}$ (Fig. $5.9, b)$. The distance becomes larger than the equilibrium distance for the force field. Consequently, the particle will again approach the interface to a distance $d_{F}$ (Fig. 5.9,c). This interplay between the two equilibrium distances will continue, and steady state will not be reestablished. The particle will sink continuously in 
the solid. The borders of the gap will close behind the particle, resulting in engulfment (Fig. 5.9,d). Coupled with this is the phenomenon of general destabilization of the interface because of the alteration of the thermal field.

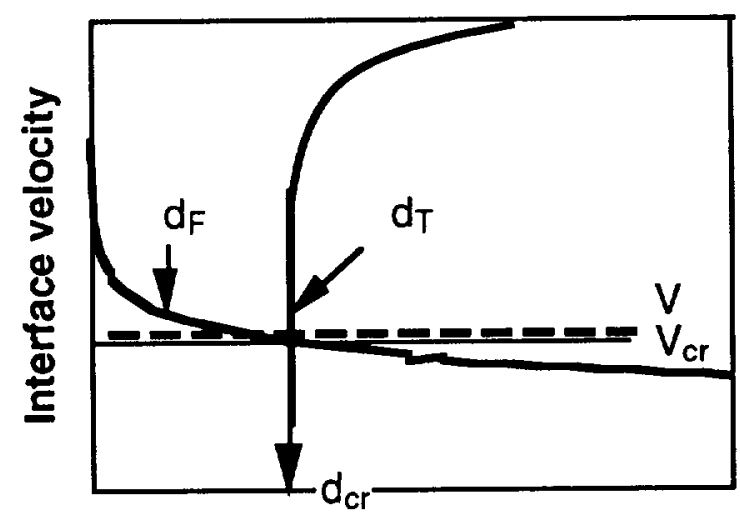

Distance from interface

Fig. 5.8 Schematic representation of the difference between the equilibrium distance for the force field, $d_{F}$, and that for the thermal field, $d_{T}$, when interface velocity is higher than the critical velocity.

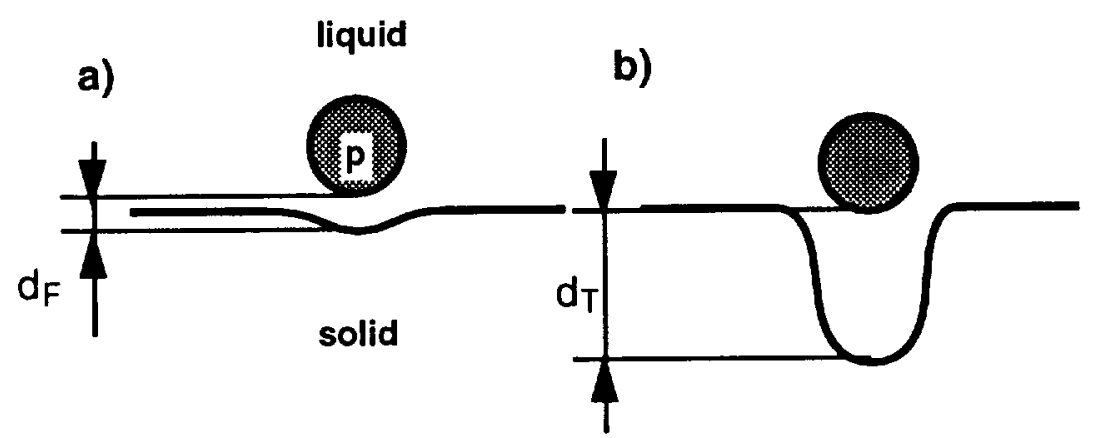

c)

d)
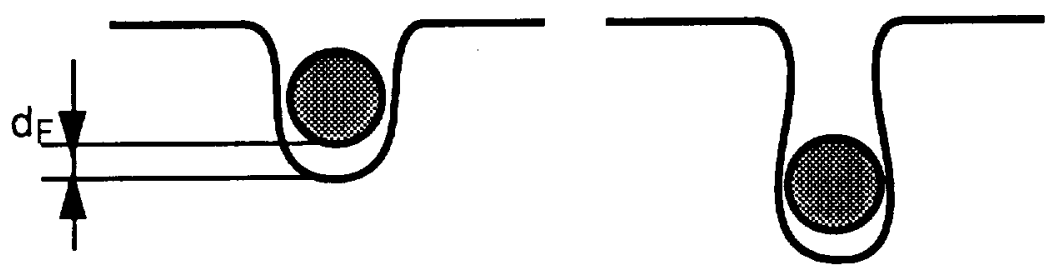

Fig. 5.9 Trough formation and engulfment of a particle by an interface traveling at a velocity higher than the critical velocity. 
Experimental evidence of significant trough formation because of the influence of the particle on the thermal field at the interface was shown in Fig. 5.7 for a succinonitrile/SiCp system. Note that if $V$ is slightly higher than $V_{c r}$, trough formation is readily observable (Fig. 5.7,b). On the contrary, if $V>V_{c r}$, engulfment is very rapid, and no significant trough is observed experimentally (Fig. 5.7,a). A comparison between calculated and experimentally evaluated data for this system are given in Table 5.2. Note that the calculated critical velocity for $\mathrm{n}=1.5$ was $4 \mathrm{~mm} / \mathrm{s}$, while the experimental data showed a critical velocity between 9.2 and $21 \mathrm{~mm} / \mathrm{s}$. The predicted value is thus reasonably close to the experimental one.

Experimental data obtained by Bolling and Cisse [5.10] on a water/tungsten system given in Table 5.2, show that the critical velocity for a particle having a radius of $5 \mathrm{~mm}$ is approximately $1.8 \mathrm{~mm} / \mathrm{s}$ for a gradient of $10^{\circ} \mathrm{C} / \mathrm{cm}$. Calculation of the $V$-- $d$ curves for a $5 \mathrm{~mm}$ radius tungsten particle in water are shown in Fig. 5.10. The data used for calculation are given in Table 5.1, Appendix of this chapter. From Fig. 5.10 a critical velocity of $0.8 \mathrm{~mm} / \mathrm{s}$ is predicted for $n=1.5$, and of $0.1 \mathrm{~mm} / \mathrm{s}$ for $n=1.8$. Given the incertitude in the evaluation of $n$ and $\Delta \sigma_{0}$, the calculated value for $n=1.5$ is in reasonable agreement with the experimental results.

Table 5.2 Experimental and calculated data on the critical velocity for various systems.

\begin{tabular}{|c|c|c|c|c|c|}
\hline \multirow[t]{2}{*}{ System } & \multirow[b]{2}{*}{$\begin{array}{l}\text { Particle } \\
\text { dia., mm }\end{array}$} & \multicolumn{3}{|c|}{ Experimental } & \multirow{2}{*}{$\begin{array}{c}\text { Calculated } \\
\text { Vcr, } \mathrm{mm} / \mathrm{s} \\
\mathrm{n}=1.5\end{array}$} \\
\hline & & Interface & $\begin{array}{c}\mathrm{Vcr} \\
\mathrm{mm} / \mathrm{s}\end{array}$ & Ref. & \\
\hline \multicolumn{6}{|c|}{$\mu>1$} \\
\hline $\begin{array}{l}\mathrm{SCN} / \mathrm{SiC} \\
\text { water/tungsten }\end{array}$ & $\begin{array}{c}8 \\
10 \\
\end{array}$ & $\begin{array}{l}\text { planar } \\
\text { planar }\end{array}$ & $\begin{array}{l}9.2 \\
1.8 \\
\end{array}$ & {$[10]$} & $\begin{array}{c}4 \\
0.8 \\
\end{array}$ \\
\hline \multicolumn{6}{|c|}{$\mu<1$} \\
\hline Al-2wt. $\% \mathrm{Mg} / \mathrm{SiC}$ & $50-150$ & cellular & 400 & {$[7]$} & 80 \\
\hline
\end{tabular}




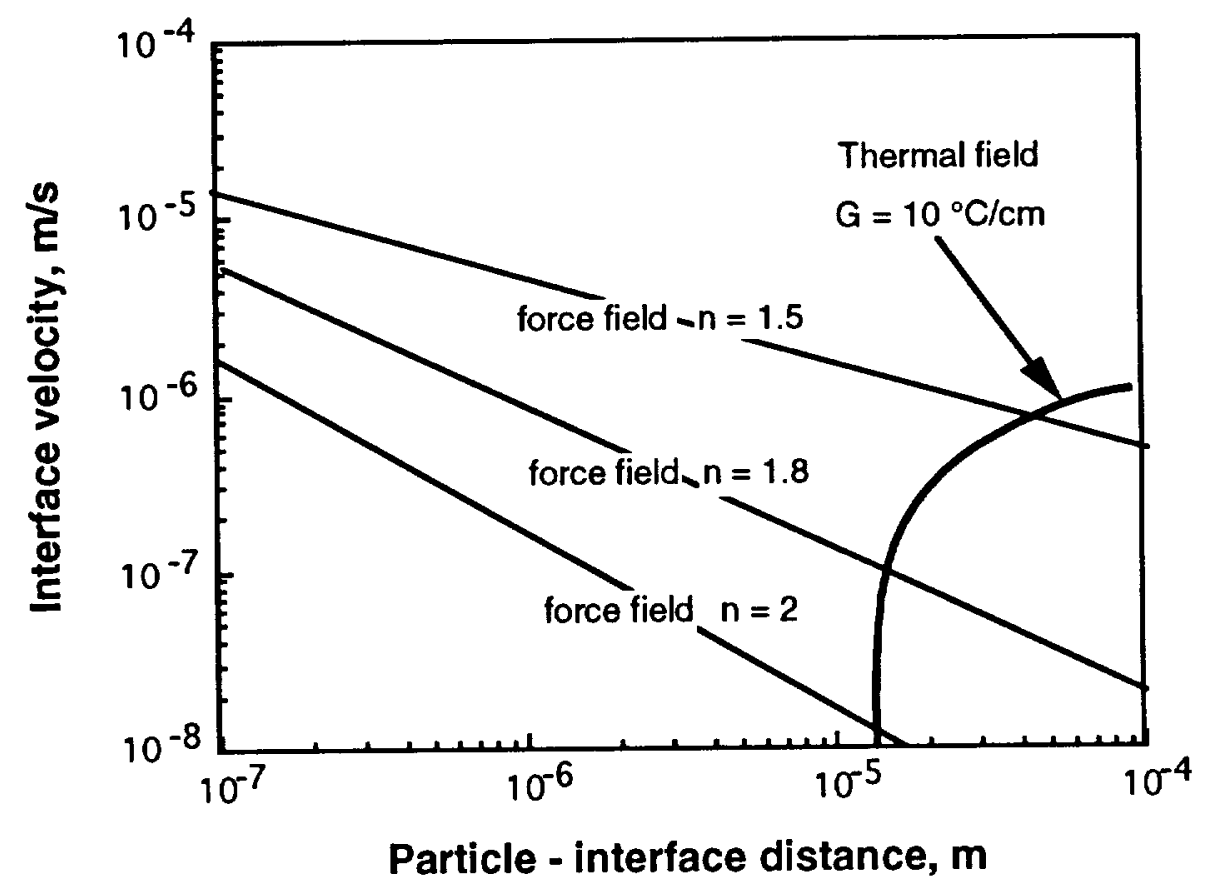

Fig. 5.10 Evaluation of critical velocity for a $5 \mathrm{~mm}$ radius tungsten particle in water for two values of $n$ in Eq.(5.2).

The temperature gradient will influence both the critical velocity and the critical distance, according to Eq. (5.18). However, its influence is rather limited. The level of gradient effect can be assessed from Eq. 5.18. It can be seen on Fig. 5.5 that as the gradient increases from 90.6 to $108^{\circ} \mathrm{C} / \mathrm{cm}$, for $n=1.5$, the critical velocity increases from 3 to $4 \mathrm{~mm} / \mathrm{s}$, while the critical distance decreases from 10.24 to $8.74 \mathrm{~mm}$. These trends agree with the influence of gradient proposed in the numerical model of Potschke and Rogge [5.6]. They suggest that for a given particle radius the influence of the gradient is given by a relationship $V_{c r}=$ cons. $\cdot$ G0.5. This kind of dependency is in line with the experimental measurements reported by Korber et al. [5.11] on the water -- latex particles system.

It has been demonstrated by many authors $[5.1,5.6,5.7,5.8]$ that the critical velocity decreases as the particle radius increases, following a power law. Calculations with the proposed model presented in Fig. 5.11 also confirm this type of dependency. 


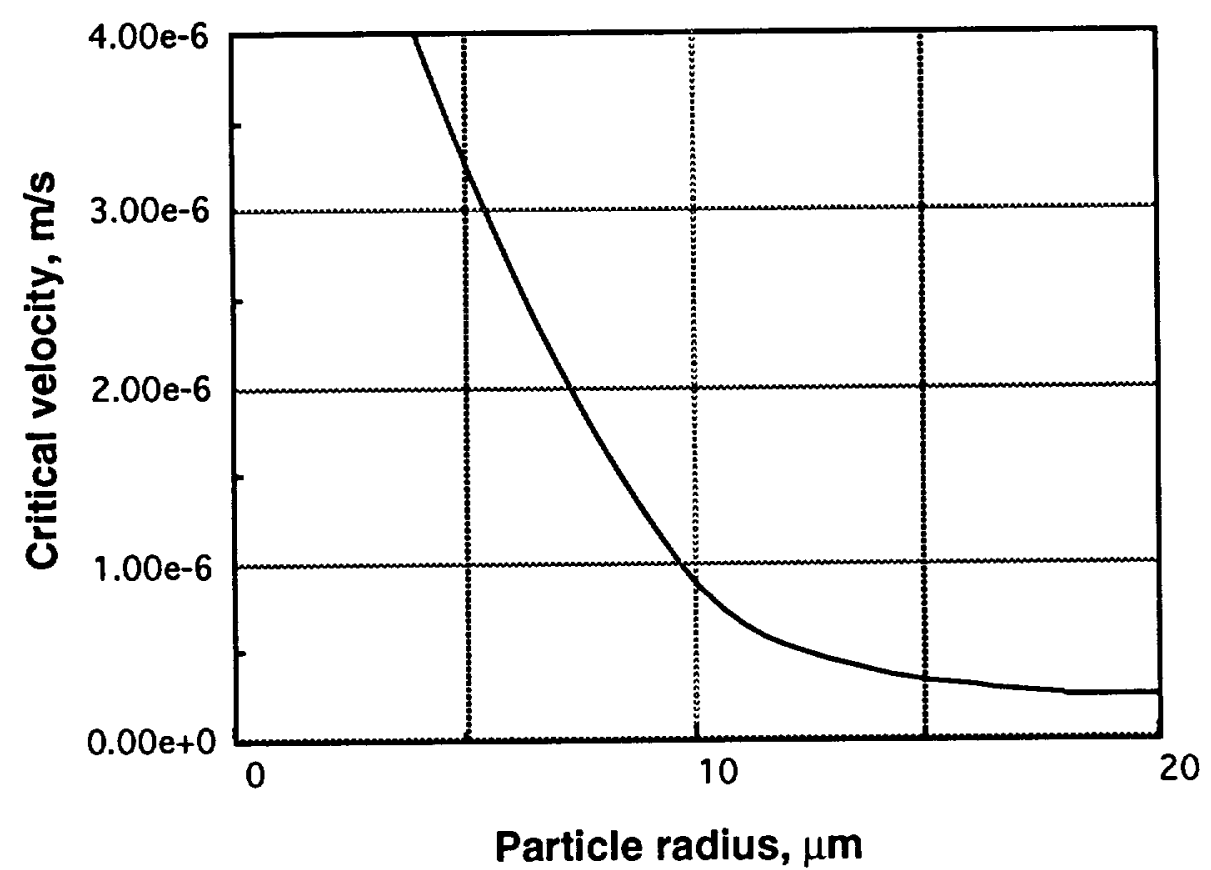

Fig. 5.11. Relation between critical velocity and radius of particle for the succinonitrile/SiCp system, using $n=1.5$.

\section{B. Case 2: $\mathrm{Kp} / \mathrm{Km} \leq 1$}

According to the proponents of the "thermal conductivity criterion" model [5.4,5.12], when $\mu=\mathrm{K}_{\mathrm{P}} / \mathrm{K}_{\mathrm{L}}<1$, a bump rather than a depression should form at the liquid/solid interface. Indeed, a qualitative analysis of the thermal field by Bolling and Cisse [5.10], as well as the analytical model proposed by Stefanescu et al. [5.7.5.8], suggest the formation of such bumps on the interface. However, these analyses ignore the latent heat evolved during solidification. This heat can be "trapped" between the particle and the interface, because of the lower thermal conductivity of the particle. Thus the interface will be depressed, and a depression rather than a bump may form. However, when $K_{P} / K_{L} \ll 1$, a bump can form.

Some experimental data reported in the literature for systems that have $m$ $\leq 1$ are given in Table 5.2. Unfortunately, the data for the two systems based on aluminum matrix are not for planar interface but for columnar or cellular interface. It is expected that the morphology of the interface will affect the critical velocity 
[5.7], although no quantitative treatment has been proposed so far. For the Al/SiC system the experiment ${ }^{[5.7]}$ showed that most of the particles were engulfed at $V$ $=400 \mathrm{~mm} / \mathrm{s}$, but some were still pushed. Thus, this velocity can be considered slightly smaller than the critical velocity. The calculated value of $80 \mathrm{~mm} / \mathrm{s}$, as shown in Fig. 5.12, is reasonably close to the experiment.

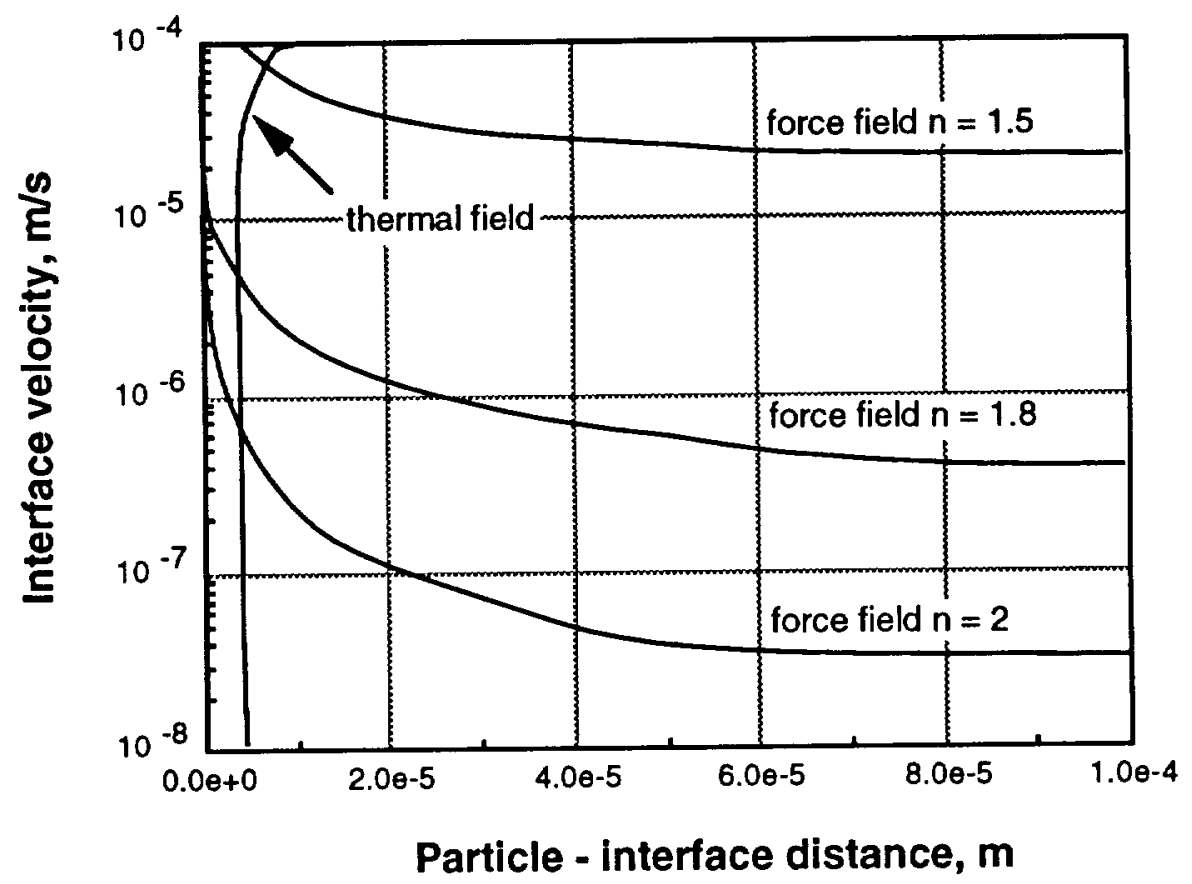

Fig. 5.12. Influence of assumption made for $n$ in Eq.(5.2) on the calculated critical distance for the aluminum/SiC system. Particle radius is $25 \mu \mathrm{m}$.

\subsection{Summary}

Through combined thermal field and force field calculation a model for prediction of particle behavior at the liquid -- solid interface was developed. The model is based on the hypothesis that both thermal equilibrium and force equilibrium must be achieved at the interface during steady state pushing of the particle when the particle is pushed at a distance higher than the atomic distance. If thermal equilibrium cannot be achieved, the particle can still be pushed, but the separation distance between the particle and the interface is of the order of the atomic distance. Two basic equations were derived. They were used for the calculation of the thermal and force equilibrium distance as a function of the solidification velocity. By coupling these equations a unique value can be found for the critical velocity. 
The thermal field equation derived predicts the formation of bumps and troughs on the melt interface behind the particles. However, it demonstrates that the condition $\mathrm{K}_{\mathrm{P}} / \mathrm{K}_{\mathrm{L}}<1$ is not sufficient for bump formation. Limited effects of the thermal gradient on the critical velocity are also predicted. The conclusions of earlier researchers are thus confirmed. The occurrence of the bending of the interface was documented through experiments on transparent matrix materials (succinonitrile) containing $\mathrm{SiC}$, and polystyrene particles.

Model validation through calculation with data from the present experiments as well as from experiments performed by other researchers on water -- tungsten and aluminum -- SiC systems showed reasonable agreement. The model allows an approximate evaluation of the exponent used in the definition of the repulsive force based on surface energy.

The present model is applicable to particulate metal matrix composites. It can be used to predict particle distribution in such composites solidifying with equiaxed structure, and inclusion distribution in castings.

\subsection{Appendix 2}

Table 1 Physical constants used in the calculation of the critical velocity.

\begin{tabular}{|c|c|c|c|c|c|}
\hline $\begin{array}{l}\text { Physical } \\
\text { constants }\end{array}$ & $\begin{array}{c}\text { Succinonitrile - } \\
\text { SiC } \\
\end{array}$ & $\begin{array}{c}\text { Succinonitrile - } \\
\text { Polystyrene }\end{array}$ & $\begin{array}{l}\text { Water - } \\
\text { tungsten }\end{array}$ & Aluminum - SiC & $\begin{array}{c}\text { Aluminum - } \\
\mathrm{Al}_{2} \mathrm{O}_{3}\end{array}$ \\
\hline$a_{0}(m)$ & $5.9 \cdot 10^{-10}$ & $5.9 \cdot 10^{-10}$ & $2.76 \cdot 10^{-10}$ & $1.43 \cdot 10^{-10}$ & $1.43 \cdot 10^{-10}$ \\
\hline$h\left(\mathrm{~kg} \mathrm{~m}^{-1} \mathrm{~s}^{-1}\right)$ & 0.0026 & 0.0026 & 0.001004 & 0.0014 & 0.0014 \\
\hline$K_{p}\left(W m^{-1} K^{-1}\right)$ & 85 & 0.0794 & 167.36 & 85 & 3.35 \\
\hline$K L\left(W m^{-1} K^{-1}\right)$ & 0.223 & 0.223 & 0.599 & 93 & 93 \\
\hline$r_{p}\left(\mathrm{~kg} \mathrm{~m}^{-3}\right)$ & 3220 & 1060 & 19350 & 3220 & 3900 \\
\hline$r_{m}\left(\mathrm{~kg} \mathrm{~m}^{-3}\right)$ & 986.7 & 986.7 & 998.2 & 2357 & 2357 \\
\hline$C_{p p}\left(\mathrm{~J} \mathrm{~kg}^{-1} \mathrm{~K}^{-1}\right)$ & 1171.52 & - & 3.76 & - & - \\
\hline$C_{p m}\left(J_{k g}^{-1} K^{-1}\right)$ & 2026.95 & 2026.95 & 4183.0 & 1079.5 & 1079.5 \\
\hline$\Delta \sigma_{0}\left(\mathrm{~N} \mathrm{~m}^{-1}\right)^{\star}$ & $10^{\star}$ & $10^{*}$ & $5 *$ & $8.27[7]$ & $10^{*}$ \\
\hline $\mathrm{T}_{\text {soak }}(\mathrm{K})$ & 353.0 & 353.0 & 298.0 & - & - \\
\hline $\mathrm{T}_{\text {int }}(\mathrm{K})$ & 328.0 & 328.0 & 273.0 & - & - \\
\hline $\mathrm{G}_{\mathrm{S}}\left({ }^{\circ} \mathrm{C} \mathrm{m}^{-1}\right)$ & 8000 & 8000 & 8000 & 3000 & - \\
\hline $\mathrm{G}_{\mathrm{L}}\left({ }^{\circ} \mathrm{C} \mathrm{m}^{-1}\right)$ & 10800 & 10800 & 10800 & 9500 & $\cdot$ \\
\hline$\Delta \mathrm{H}\left(\mathrm{J} \mathrm{m}^{-3}\right)$ & $4.6 \cdot 10^{7}$ & $4.6 \cdot 10^{7}$ & $3.33 \cdot 10^{8}$ & $9.5 \cdot 10^{8}$ & $9.5 \cdot 10^{8}$ \\
\hline
\end{tabular}

*Data are unavailable. These numbers were assumed to be reasonable. 


\section{List of Symbols Chapter 5}

$\mathrm{C}_{\mathrm{pp}} \quad$ Specific heat of the particle

$\mathrm{C}_{\mathrm{pm}} \quad$ Specific heat of the matrix

$G_{L} \quad$ Temperature gradient in the liquid at distance $L+R$ from the origin

Gs Temperature gradient in the solid at the solid/liquid interface

G'L Temperature gradient in the liquid film between the particle and the solid/liquid interface

$K_{p} \quad$ Thermal conductivity of particle

$\mathrm{KL}_{\mathrm{L}} \quad$ Thermal conductivity of liquid matrix

$\mathrm{K}_{S} \quad$ Thermal conductivity of solid matrix

$\mathrm{R} \quad$ Particle radius

T Temperature

$T_{m} \quad$ Temperature in the matrix

Tint Temperature of the solid/liquid interface

$T_{p} \quad$ Temperature of the particle

$T_{\text {soak }}$ Soak temperature

$\checkmark \quad$ Interface velocity

$V_{c r} \quad$ Critical velocity

$V_{\mathbf{e}} \quad$ Equilibrium velocity

$a_{0} \quad$ Atomic distance

d Separation between the particle and the melt interface

g Acceleration due to gravity

$\mathrm{m} \quad$ Thermal conductivity ratio $\left(=\mathrm{K}_{\mathrm{p}} / \mathrm{K}_{\mathrm{m}}\right)$

$\eta \quad$ Melt viscosity

$\rho_{p} \quad$ Particle density

$\rho_{m} \quad$ Matrix density

$\Delta \rho \quad$ Density difference

$\Delta \sigma_{0} \quad$ Interfacial energy difference $\left(=\sigma_{\mathrm{sp}}-\sigma_{\mathrm{lp}}-\sigma_{\mathrm{sl}}\right)$

$\sigma_{\mathrm{sp}} \quad$ Solid/particle interfacial energy

$\sigma_{\mathrm{sl}} \quad$ Solid/liquid interfacial energy

$\sigma_{\text {lp }} \quad$ Liquid/particle interfacial energy

$\Delta \mathrm{H} \quad$ Latent heat of fusion for the matrix

Subscripts

int: Interface l: Liquid m: Matrix p: Particle 


\section{References Chapter 5}

5.1. S.N. Omenyi and A.W. Neumann: J. Appl. Phys., 1976, vol. 47, no. 9, p. 3956

5.2. P.S. Mohanty, F.H. Samuel and J.E. Gruzleski: Metall. Trans., 1993, vol. 24A, p. 1845

5.3. D.R. Uhlmann, B. Chalmers and K.A. Jackson: J. Appl. Phys., 1964, vol. 35, no. 10, p. 2986

5.4. G.F. Bolling and J. Cisse: J. Cryst. Growth, 1971, vol. 10, p. 56

5.5. A.A. Chernov, D.E. Temkin and A.M. Melnikova: Sov. Phys. Crystallogr., 1976, vol. 21, no. 4, p. 369

5.6. J. Potschke and V. Rogge: J. Crystal Growth, 1989, vol. 94, pp. 726-738.

5.7. D.M. Stefanescu, B.K. Dhindaw, A.S. Kacar and A. Moitra, Metall. Trans., 1988, vol. 19A, pp. 2847-2855

5.8. D. Shangguan, S. Ahuja and D.M. Stefanescu: Metall. Trans. A, 1992, vol. 23A, pp. 669-680

5.9. S. Ahuja, D. Shangguan and D.M. Stefanescu, in Advanced Metal Matrix Composites for Elevated Temperatures Conference Proceedings, M.N. Gungor, E.J. Lavernia and S.G. Fishman editors, ASM International, Ohio, 1991, pp. 205-212

5.10. G.F. Bolling and J. Cisse: J. Cryst. Growth, 1971, vol. 11, pp. 25-28

5.11. C. Korber, M. D. Cosman and E.G. Cravalho, J. Crystal Growth, 1985, vol. 72, p. 649

5.12. A. M. Zubko, V. G. Lobanov and V. V. Nikonova: Soviet Physics Crystallography, 1973, vol. 18, pp. 239-241. 